\title{
Modeling Overlapped Mutual Funds' Portfolios: A Bipartite Network Approach
}

\author{
Jaime F. Lavin $\mathbb{D}^{1},{ }^{1}$ Mauricio A. Valle, ${ }^{2}$ and Nicolás S. Magner ${ }^{2}$ \\ ${ }^{1}$ Escuela de Negocios, Universidad Adolfo Ibáñez, Diagonal Las Torres 2640, Peñalolén, Santiago, Postal Code 7941169, Chile \\ ${ }^{2}$ Facultad de Economia y Negocios, Universidad Finis Terrae, Pedro de Valdivia 1509, Providencia, Santiago, \\ Postal Code 7501015, Chile \\ Correspondence should be addressed to Jaime F. Lavin; jaime.lavin@uai.cl
}

Received 12 February 2019; Accepted 3 June 2019; Published 1 July 2019

Guest Editor: Benjamin M. Tabak

Copyright (c) 2019 Jaime F. Lavin et al. This is an open access article distributed under the Creative Commons Attribution License, which permits unrestricted use, distribution, and reproduction in any medium, provided the original work is properly cited.

\begin{abstract}
This paper studies the topology of the Chilean mutual fund industry using networks methods. With the physical positions of the local equity portfolios managed during 2003.01-2017.4, we analyze their connectivity structure in both the mutual funds' bipartite network and their one-mode projection. We estimate network measures to examine the potential effects on the topology arising from changes in the industrial environment and changes in the mutual funds' investment strategies in their overlapped portfolios. Our main results show that changes in the bipartite network and its one-mode projection are correlated with variables related to funds' investment strategies and with industry-specific variables. In consequence, these elements are a new potential of disturbance in the financial network conformed by stocks and mutual funds. We contribute to the existing literature, improving the understanding of the aggregate behavior of a financial sector which despite its economic importance has attracted little attention from a systemic risk perspective.
\end{abstract}

\section{Introduction}

This paper studies the topology of networks in the mutual fund industry by analyzing the composition of their investment portfolios. Application of a network analysis makes it possible to identify and analyze the interrelation existing between mutual funds that share investments in similar financial assets, using bipartite networks and its one-mode projection. This phenomenon, called overlapping, is a financial network of assets and funds. Understanding the topology of this network is critical, because the assets that each fund allocates affect its financial performance, as the financial literature indicates, and impact the structure of the industry. Consequently, it influences the stability and propagation of financial contagions, such as firesales of assets and runs on mutual funds. As a result, this affects risk and industry development.

During the subprime crisis, investors favored liquid assets (liquidity hoarding) and those free of risk (flight to quality) at the cost of stocks and bonds, significantly affecting the price of financial assets [1]; stocks and bonds suffered drops in their prices that negatively affected the performance of stockbrokers and fund managers, such as mutual funds, commercial banks, pension funds, and hedge funds. As a result, this behavior is recognized as a contagion for the rest of the financial system $[2,3]$.

The losses inflicted by the crisis highlighted for policymakers, regulators, and academics the importance of assessing the systemic risk and understanding the propagation mechanisms of financial shocks. The crisis made the complexity, instability, and fragility of the existing network structures in the capital markets a tangible reality $[4,5]$. As a result, the financial system, particularly the banking system, garnered the attention of the networks literature to study its structure and how changes to it affect the probability of occurrence and spread of financial contagions.

The financial literature identifies two channels of financial crisis contagion. The first, related to direct exposure between two agents, is produced by bilateral asset transactions or contracts, such as credit operations and credit default swaps [2]. The second, called portfolio overlaps, is linked to indirect exposure generated between two or more investors such as 
pension funds, hedge funds, and mutual funds that have exposures in the same financial asset [6]. However, despite the size of these investors in the financial system, the literature pays little attention to the second channel ${ }^{1}$. The present study focuses on studying the complexity of the phenomenon of portfolio overlaps through network analysis.

The study of the phenomenon of systemic risk through overlapping portfolios is novel $[4,7]$; however, there is a lack of studies applied to the mutual fund industry, despite its importance and $\operatorname{size}^{2}$. Delpini and others [8] analyze the bipartite network of US mutual funds during the financial crisis, studying how the systemic fragility of the system depends on the overlap between portfolios. Their results indicate that diversification and similarity in financial investment strategies are factors that increase distress propagation and systemic fragility. The authors confirm that diversification increases systemic risk when the funds use the same investment strategies and diversify using similar assets.

The relation between diversification and systemic risk is important due to the effect of both factors on investment portfolio management. Markowitz [9] argues that diversification, achieved by increasing the number of assets in a portfolio, reduces the unsystematic risk. This definition, however, does not consider the contribution of the overlapping of assets to systemic risk and the propagation of shocks at the aggregate level. In this sense, the network methodology can complement the study of financial risk, analyzing the composition and diversification of portfolios from the same group of investors, as well as of the degree of similarity of the assets that make up their portfolios and of the investment strategies used.

The above reveals the tension existing within portfolio management and the influence of diversification as a tool for risk management. Although diversification reduces the systematic risk of the assets when this occurs in the presence of high similarity in the portfolios, as in the mutual fund industry, for example, diversification becomes a generator of systemic risk. This occurs because by holding diversified portfolios but comprised of the same assets, the funds return to the system as a more vulnerable whole because the interconnections and channels of contagion are increased $[3,10]$.

An understanding of the risks generated by a portfolio manager that seeks to minimize them through diversification increases the interdependencies on the portfolio overlap networks of mutual and pension fund managers. This phenomenon acquires significance as an amplifier and generator of financial shocks, even more so in small economies with little diversity of assets to invest as is the case in emerging countries.

Nevertheless and contrary to expectations, there is still little attention paid in the literature to the study of financial risks in this intermediary segment [8] and, to our best of knowledge, even nonexistent in a context of emerging markets. The segment of institutional investors includes mutual funds, hedge funds, and pension funds; it is one of the primary investment vehicles globally. They reached a size of USD 46.17 trillion equivalent to $61 \%$ of global GDP in the first quarter of 2017. Mutual funds reached a size of USD 42.77 trillion, the most important group in this industry. $65 \%$ of the managed assets correspond to stocks and debt instruments, with $43 \%$ of total participation being equity funds. These numbers underscore the relevance of these investors, and the need to deepen understanding of the effects of these intermediaries' investment strategies on financial risk in this industry.

The use of networks has made it possible to study mainly the structures of control chains in financial systems, systemic risk, the evolution of commerce between nations, and interbank transactions between banks [11]. These papers consider similarity-based networks, in which the weights of a network represent a measurement of similarity (or distance) between assets; this measurement is a linear correlation between the returns on the assets. The correlation then becomes a distance associated with a Euclidian distance, which is why hierarchical clustering methods can be applied to understand the industry-specific structure and clusters. Also, using the network approach, it is possible to detect the relations between different market agents to discover the underlying control chains $[12,13]$. Finally, in the study of transactions between two agents, the links represent the transactions, whereas the nodes represent the agents in the financial market. For example Boss and others [14], study the formation of community structures and other topological elements of the networks that show free scale and small world properties. However, there is a gap in the literature respect to the relation between topological elements of the financial network, the variables of asset management, and industry variables. For example, in the case of mutual funds, how does the path length of the network vary when portfolios managers begin increasing the sale of assets to buy others, or when they decide to increase or reduce the diversification of their portfolios?

Given the logical evolution of the literature on financial networks analysis and to contribute to a deeper understanding of the portfolio overlaps phenomenon in a mutual fund industry context, this study aims to examine how financial management variables in conjunction with specific variables from the mutual fund industry, mold, and shape financial networks between funds and financial assets.

Accordingly, in this work we study the following hypotheses:

(1) the topology of the mutual funds network changes due to variations in the investment strategies selected by the industry actors.

(2) the topology of the mutual funds network changes due to variations in industry-specific variables.

Our research contributes to the literature by improving the understanding of the phenomenon of overlapping from three perspectives. First, we analyze the topology of the mutual funds network using a bipartite network method (similar to Delpini and others [8]), and we complement it with an analysis of its bipartite one-mode network projection (for a summary see Zhou and others [15] and Straka et al. [5]). Second, we study the effect of economic and financial shocks that affect the equity market as a whole on the topological properties of the funds network. And third, we consider studying the impact of changes in the mutual fund's 
investment strategies ${ }^{3}$ on the basic characteristics of the topology of the network of funds from an emerging market like Chile.

Additionally, we add more depth to the analysis by including network parameters such as diversity, modularity, path length, and assortativity. This is important because the financial phenomenon that involves managing mutual fund assets consists in studying the effect of changes on industry variables, understanding how these intermediaries manage their investments in the event of fluctuations in the financial context, the degree to which they use similar investment strategies, and how much they increase or reduce the diversification of their portfolios.

We study the mutual fund industry because it is the most important financial intermediary in terms of volume of managed assets, invest in the same class of assets and markets, and there is high similarity in their investment strategies and composition; factors that increase the systemic risk of the phenomenon of portfolio overlaps. Finally, our study makes a methodological variation by using bipartite network projections to analyze the extent to which asset overlapping determines the level of interdependence between mutual funds in the same market, in the event of changes in their investment strategies, and fluctuations in industry conditions.

The main results show that the structures of the bipartite mutual fund network and its one-mode projection change over time and are affected by variables related to the fund investment strategies and industry-specific variables. By studying the phenomenon of portfolio overlapping in a segment of investors who invest in the same asset class in the same country, we have found that their behavior affects the structure of the financial network comprised of their funds and the stocks where these invest. This endogenous element is derived from the financial strategies that funds use when they are fulfilling their role as third-party fund managers. This is an additional factor of changes in the structures of the financial networks which has effects on financial stability and risk.

The rest of the paper is structured as follows: in Section 2, we explain the bipartite network and its one mode projection. In Section 3, we describe our data and explain our focus on the Chilean mutual fund industry. In Section 4, we characterize the mutual fund industry using bipartite networks and their one-mode projection. In Section 5, we present the methodology, econometric results, and robustness analysis. Finally, in Section 6, we conclude and provide future research extensions.

\section{Model}

This section describes how to model the interdependencies between mutual fund managers using a network approach. The network approach offers us the possibility of analyzing the structure and temporal dynamics of these interdependencies, created as a product of decisions about investing in stocks. These purchase and sale decisions are those that ultimately impact the topology of the mutual funds network.
An appropriate network to model the interdependencies between funds and stocks is through a bipartite network. We begin with this description, which gives us the input to project this network in a one-mode. That is a network that represents only the interdependencies between mutual funds.

The bipartite networks are useful for studying situations where financial institutions possess overlapping exposures to different asset classes. The bipartite network has two types of nodes: mutual funds-entities that manage investments - and stocks, denoted by $\mathrm{U}$ and $\mathrm{V}$, respectively. We denote with $\mathrm{E}$ the links that join the two types of nodes, which are disjointed between them. Each node is linked to a weight $\mathrm{w}_{\mathrm{ij}}$ that represents the level of exposure of the mutual fund $i$ on the asset $j$. Then $G(U, V, E)$ is a weighted bipartite network since each element of $E$ connects a vertex of $U$ and $\mathrm{V}$ such that there are no edges that connect elements of $\mathrm{U}$ and $\mathrm{V}$ between them. The links that go from funds to stocks represent diversification, whereas the weights of the bipartite network are equivalent to the exposure of the funds in stocks.

Figure 4(a) shows an example of a bipartite network between mutual funds and stocks. It shows three different cases with different exposures (different weights), but always with the same level of diversification. We analyze the bipartite network using three properties. The first is the degree of the set of nodes corresponding to the mutual funds, which measures the level of diversification of the funds in the stocks. The second is the strength, which measures the level of exposure of the fund to the stocks. Finally, we calculate the diversity, which measures the complexity of a mutual fund given by its diversification and exposure.

The bipartite network tells us how mutual funds and stocks are connected between them. But how do mutual funds relate to each other? The answer is given by the stock portfolios they share. Thus, we propose to compress the bipartite network by one-mode projection to understand how mutual funds relate to each other.

There are different methods to project a bipartite network to a one-mode projection. In particular, for a weighted bipartite network, the resulting weighted adjacent matrix $\left\{\mathrm{w}_{\mathrm{km}}\right\}$ will always be symmetrical, i.e., $\mathrm{w}_{\mathrm{km}}=\mathrm{w}_{\mathrm{mk}}$. Nevertheless, the dependency of a fund $\mathrm{k}$ on a fund $\mathrm{m}$ may be different from the influence that $\mathrm{m}$ has on $\mathrm{k}$, because the funds have different levels of exposure among all the different alternatives of assets available to invest. Therefore, a more natural projection alternative is the one that allows for an asymmetrical weighting method. Consequently, we use a network resource-allocation method [15].

The result of this projection is a network in which we only observe links between nodes of the set $U$ of mutual funds, and the weights represent the degree of dependence/influence between them and not a measure of investment amounts as occurs in the bipartite network. These weights are the result of the resource-allocation method determined by [15] applied on the mutual funds that comes from the fund-byfund connection matrix, which indicates the level of reciprocal interdependence among them, generated by the shared property of the stocks. For any mutual fund $i$, it will have a weight $w_{k i}^{i n}$ that denotes the influence this fund has on fund 
$k$, while at the same time it has a weight of $w_{i k}^{\text {out }}$ that denotes that fund $i$ is also influenced by fund $k$. Therefore, to study the degree of influence and dependency of mutual funds, we focus on the strength of the projected funds network [16]. According to this methodology, the investors (mutual funds) act as retainers of resources that flow through the bipartite network. The appendix shows a simple example with two mutual funds and three stocks with different exposures and their respective one-mode projections. In this way, it is possible to understand better the relationships of dependence and influence between the funds changes.

\section{The Data}

3.1. Main Data Source. To analyze the bipartite network of mutual funds and stocks and its projection, we constructed a database with the portfolios of each mutual fund for the period January 2003 to April 2016. This study stands on the level and accuracy of the financial and industry data. For this, we obtain information from three sources, the first from the CMF (www.cmf.cl; is the Chilean equivalent of the U.S. Securities and Exchange Commission), the second from the Santiago Stock Exchange (www.sebra.cl), and the third from the Bloomberg platform (www.bloomberg.com). The dataset, free of survivorship bias, includes precise information about the price and number of portfolio stocks, the number of participants, share values, and assets under management for each mutual fund. Additionally, each stock is described by the closing price, market capitalization, trading volume, and book-to-market ratio. Thus, we can construct variables that represent the characteristics of each fund, such as the average size of the investors of the fund, return, and number of stocks where the fund invests, along with variables that according to the financial literature describe their financial strategy over time: size, liquidity, book-to-market, market capitalization, turnover, active share, and others [17-21].

Consequently, we can construct the monthly bipartite network for the Chilean mutual fund industry. To describe its topology, we calculate the degree, strength, and diversity parameters and their probability distributions for the shares on the bipartite network. Then, to extend our analysis, we estimate the bipartite network projection and calculate parameters that help us analyze the mutual fund industry in terms of its interdependencies. These variables are strength, modularity, path-length, and assortativity index.

3.2. The Chilean Mutual Fund Industry. The equity mutual fund network in Chile is interesting for many reasons. First, having accurate monthly data regarding the number of shares in each fund portfolio allows us to study in a dynamic context the networks formed by a segment of institutional investors that have not yet been studied in depth in the literature on financial networks. Second, mutual funds have enjoyed outstanding development, obtaining managed assets of MMUSD 53,887 in 2017 and reaching a penetration of $22 \%$ of GDP. This performance places them as the most dynamic investors in the Chilean delegated portfolio management industry. This figure, equivalent to $50 \%$ of the mean penetration of developed countries, is higher than the mean growth of developing countries [22]. For example, compared to 2002, when the managed amounts represented a number close to $9 \%$ of GDP, this penetration has grown to a mean rate of 5.5\% annually. This growth makes mutual funds the third actor in the delegated portfolio management industry in Chile behind pension fund administrators and insurance companies. Third, according to the World Economic Forum, the country has a medium level of financial development, since it ranks 29th out of 62 countries. Consequently, the apprenticeships gained from this industry are useful for other emerging markets on the road to more significant economic and financial development. Finally, equity markets in Chile have a high size in terms of percentage of GDP compared with other OECD markets or other emerging markets.

\section{Network Characterization of Chilean Equity Mutual Funds}

4.1. The Bipartite Network of Mutual Funds and Stocks. Financial intermediaries, such as mutual funds, fulfill three fundamental roles in providing the delegated portfolio management service. First, activities associated with economies of scale and scope enable them to reduce transaction costs; second, they invest in less liquid but more profitable assets; and, finally, they engage in delegated investment monitoring of the investments (for a survey, see Stracca [23]). Thus, in this delegated portfolio management process, every fund manager must choose from among a wide range of financial assets (equity, bonds, and deposits, mainly) to make up an investment portfolio. The main goal is to achieve the best risk-return combination for their clients.

4.1.1. Degree. The degree distribution of the mutual funds describes the typical scale-free property of the bipartite network. Figure 1 (left) represents the degree distribution of the mutual funds in the bipartite network $\left(\mathrm{k}_{\mathrm{a}}\right)$ in three different periods: before, during, and after the crisis of 2008 . Regardless of the time, we observe that few funds tend to be connected to many stocks, and the majority of the funds tend to be connected to fewer stocks. In other words, there are a few mutual funds that are highly diversified, whereas most funds are less so.

The evolution of this variable over time is in Figure 2(a). Note that there was a change in the degree of mutual funds before and after the financial crisis. Specifically, after the crisis, the mutual funds adjusted their diversification strategy to the downside and, as a result, the degree of the funds falls and increases the concentration of the funds' equity portfolios as a consequence.

4.1.2. Strength. The strength for a mutual fund $i$ is the sum of all weights of the links incident to it, indicating the exposure of the mutual fund. The weights $w_{i j}$ of a fund $i$ on an asset $j$ are related to the amounts of money in local currency that the fund $i$ has on the asset $j$ determined by the composition of its portfolio in a particular month. It is usual for these weights $w_{i j}$ to change from one month to the next reflecting the reassignment of positions (or exposures) in the mutual funds 

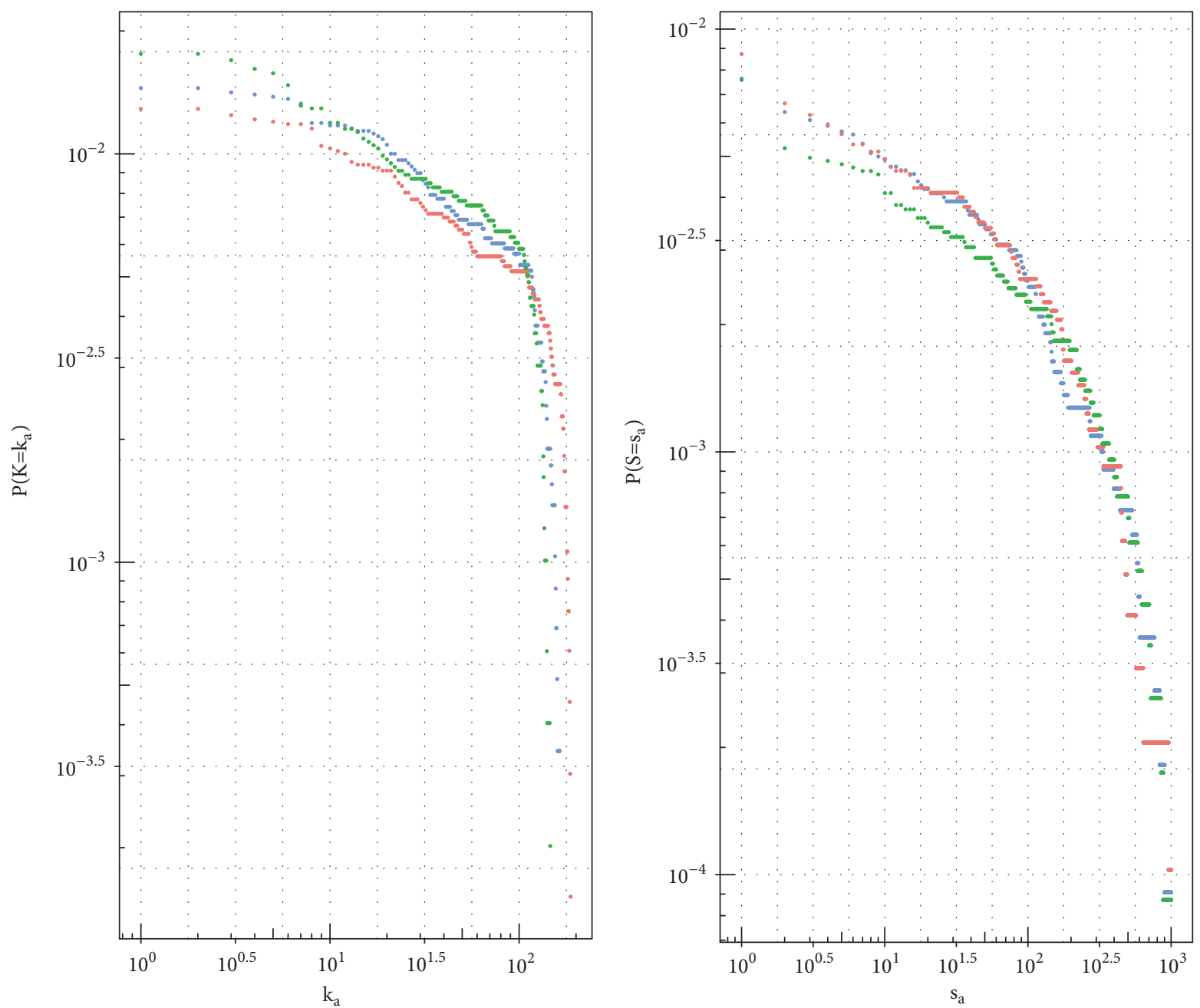

FIGURE 1: Degree $\left(\mathrm{k}_{\mathrm{a}}\right)$ and Strength $\left(\mathrm{s}_{\mathrm{a}}\right)$ densities for stocks in the bipartite networks. Different colors for each period. In blue, precrisis period from January to June 2008. In red, crisis period from June 2008 to January 2009. In green, postcrisis period from February to June 2009.

portfolio carried out as part of their particular diversification strategy.

Figure 1 (right) describes the distribution of the strength of the mutual funds in the bipartite network $\left(\mathrm{s}_{\mathrm{a}}\right)$. Regardless of the analysis period, this distribution also follows a similar behavior. A few mutual funds seem to have very high exposure in assets, whereas the vast majority have less exposure.

The evolution of this variable over time is in Figure 2(a). We observe that, during the crisis, the drop in stock prices negatively affected the strength of the network. However, contrary to expectations, the exposure did not recover during the postcrisis period despite the improvement in stock market prices. This evidence (added with the results of the degree) indicates that there was a change in the portfolios that could not be explained solely by changes in the values of the financial assets, but also by changes in the exposure of the portfolios and fluctuations in the economic and financial conditions of the equity market.

4.1.3. Diversity. If at a given moment, a mutual fund $F$ has a larger number of stocks than another mutual fund $F^{\prime}$, then fund $F$ has greater diversification than fund $F^{\prime}$. Similarly, if fund $F$ has a larger amount invested in stocks than another fund $F^{\prime}$, then fund $F$ is more exposed than fund $F^{\prime}$. In the first case, fund $F$ has a more diversified portfolio, whereas in the second, it is more exposed. To capture the combined property of the level of diversification and exposure, we used the Shannon entropy index [24]. This representation of diversity has been used to describe quantitatively the flow of biomass between different species in ecology literature [25]. For our purposes, the Shannon or entropy index for mutual fund $i$ would be

$$
H_{i}=-\sum_{j=1}^{N} \frac{w_{i j}}{w_{i *}} \log _{2} \frac{w_{i j}}{w_{i *}}
$$

where $w_{i j}$ represents, as indicated previously, the amount of money that fund $i$ has in stock $j$. The value $w_{i *}$ is the sum of all the money that fund $i$ has in its portfolio. Shannon entropy is between 0 (minimum) and 1 (maximum). In consequence, $H_{i}$ is maximum when a mutual fund invests in all the assets in its portfolio in equal proportion, that is when all $w_{i j}$ are equal for each fund and each stock. 

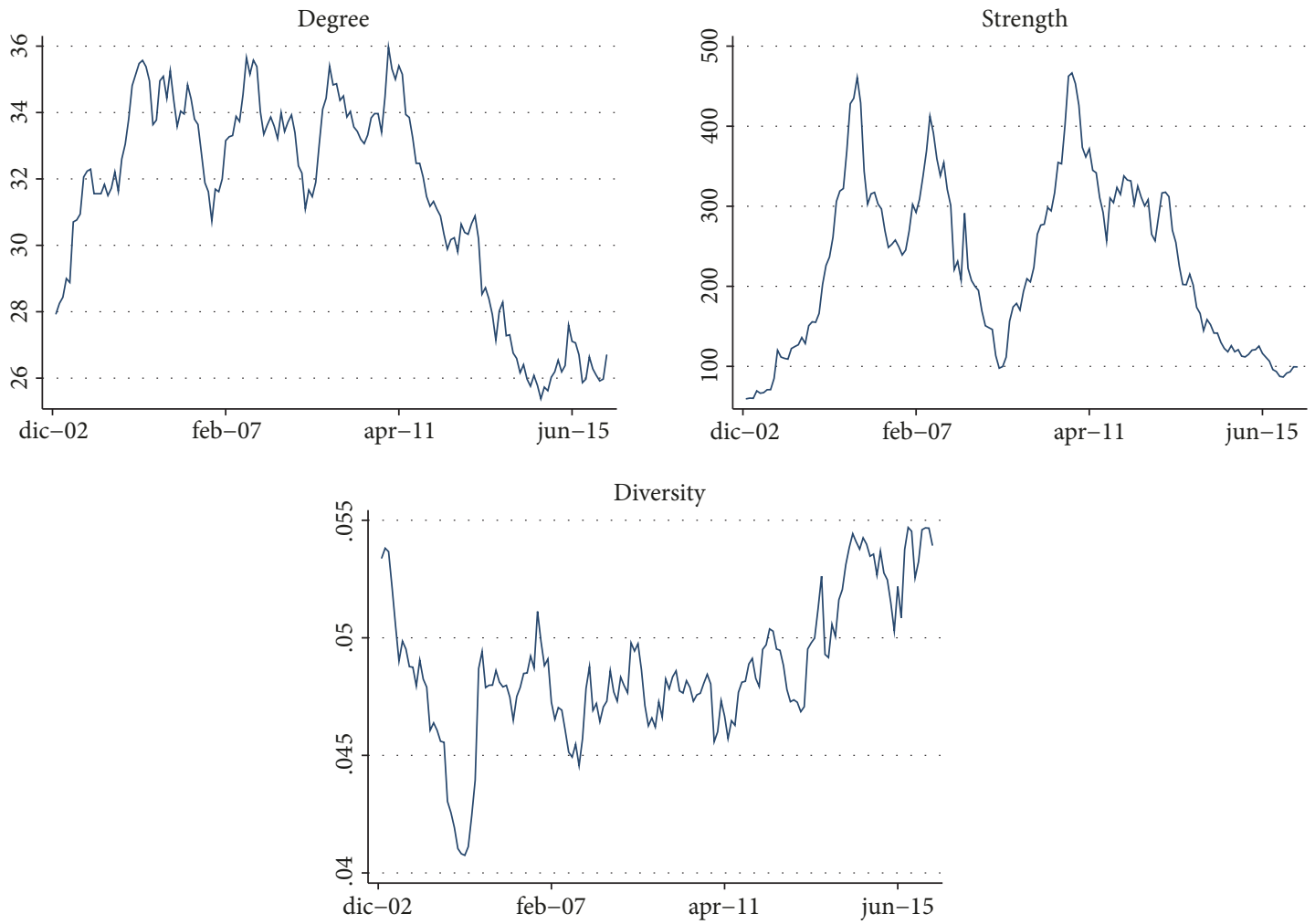

(a) Time series of bipartite networks variables
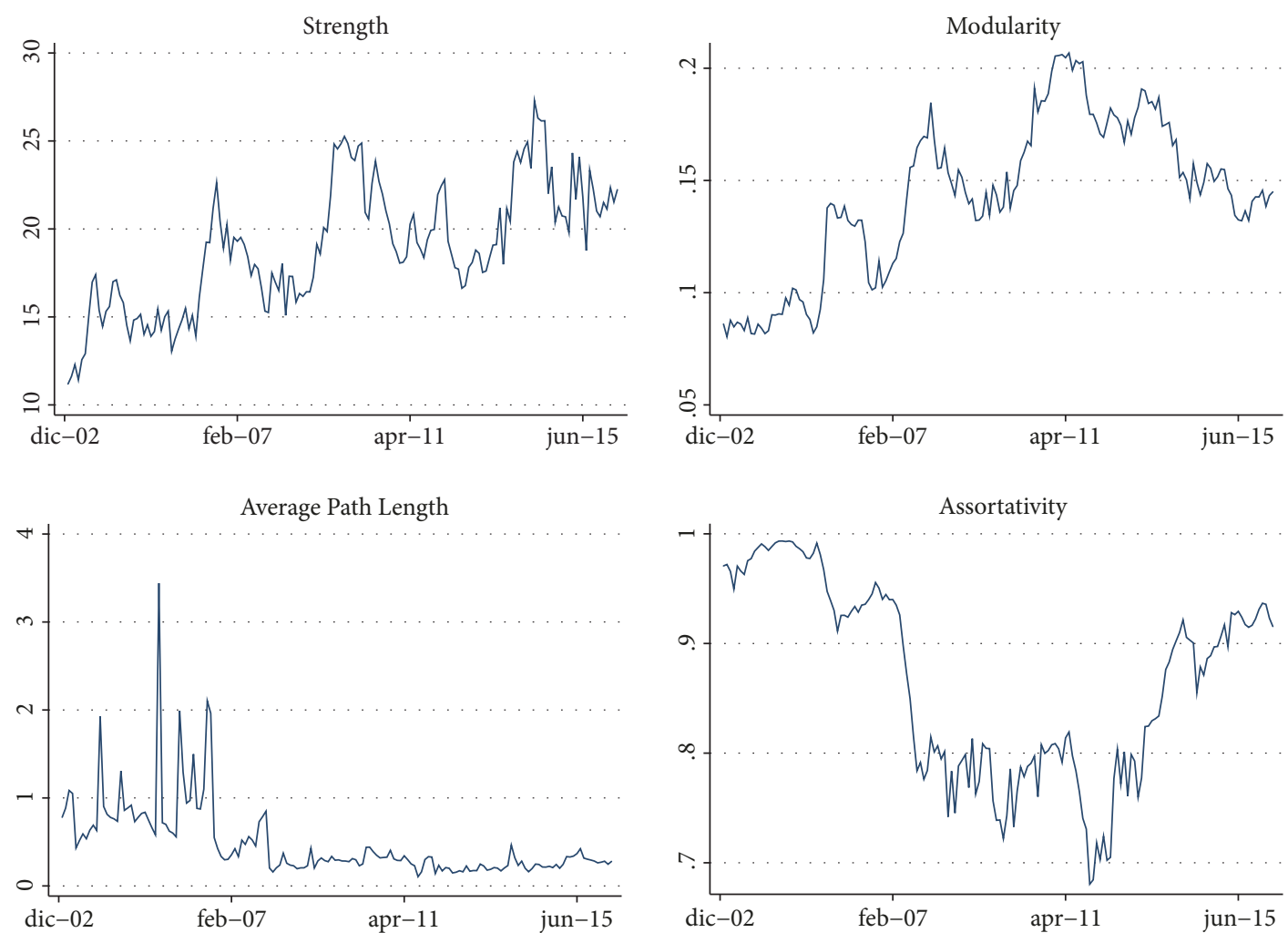

(b) Time series of bipartite network projection variables

FIgURE 2 
As the index is calculated with a logarithm in base 2, we calculate the reciprocal of $H_{i}$ and $n_{i}$ where $n_{i}=2^{H_{i}}$, which we will call general diversity. We take the average of the diversity indices of all existing mutual fund for every periods. This way, the higher the value of $n_{i}$ is, the higher the level of entropy in the industry is.

This measurement fits well to calculate the global diversity of the bipartite network from the fund managers' point of view and therefore to be able to understand how the level of industry diversification and exposure behaves in different periods. Its evolution over time is in Figure 2(a). It is possible to observe a permanent upward trend in general diversity from period April 2011 onwards. In other words, there seems to be a more focused investment in resources by funds over fewer assets (or low diversification). This could be explained by the decrease in the average degree of the system in Figure 2(a) (Degree). On the other hand, investment amounts also have a downward trend (Strength). The combined effect of these elements produces an increase in the Entropy of the industry, which suggests an effect of less exposure and diversification taken by fund managers.

4.2. The One-Mode Projection of the Bipartite Network. From the bipartite network of stocks and mutual funds, it is possible to construct a one-mode projected mutual funds network to build a network in which the funds are related only to each other. We use the one-mode projection proposed by [15] because when choosing stocks to comprise their portfolios, they share the property of some of them, and consequently overlapped portfolios are formed in the mutual fund industry, thus making it possible to study the interdependence among them.

4.2.1. Strength. The strength is the sum of the weights of the incident links to the node. As the one-mode projected network is directed, each node may have links that enter the node and others that leave it. The sum of the weights of the links that enter the node, the in-strength, measures the influence that the fund has on the others. The out-strength, the sum of the weights of the links leaving the node, measures the dependence that the fund has from the others. In this way, we have a way to measure the degree of mutual influence and dependence between the different participants in the fund industry.

As we are dealing with averages over different periods, the mean of the in-strength is equal to the mean of the outstrength, simply because in the one-mode projection process in each period, all the primary resources of the system remain intact. Thus, we speak of strength without making a difference between one and the other ${ }^{5}$.

The results indicate that the interconnection (or degree of influence of each fund on the others) of Chilean equity mutual funds is variable over time and increase during the crisis. Figure 3 shows a comparison between strengths for 12 months (a) and 24 months (b), before and after March $2009^{6}$. We observe that there is variability in the strength of the projected network. In the case of in-strength, note that, before and after the crisis, the variability stays steady, because the median and interquartile ranges are similar. However, in the crisis, we observe an increase in variability, although with values similar to the precrisis period. This is evidence of an increase in the dispersion of the dependency of the funds on each other; i.e., in the crisis the dependence of each fund increases concerning the industry, or in other words the topology of the network projection is variable over time. Similarly, the out-strength shows an increase in the median, which is not accompanied by an increase in its variability.

4.2.2. Modularity. To describe the structure of the onemode projected network, we perform a calculation of the modularity or cluster quality measure [26], considering all possible community structures based on edge-betweenness edge removals. The edge-betweenness of an edge measures the number of shortest paths that pass through it. The idea of using this measurement to detect communities within a network is that edges with a high edge-betweenness create the bridges between different communities in the network. Thus, if these edges are removed, it would clearly show areas of the network isolated one from the other, revealing the community structure.

The calculation of the modularity $Q$ is done iteratively, finding the number of communities that maximize the value of the modularity. The modularity allows us to know the degree to which specific modules in the network are more or less densely or sparsely connected to other modules [27]. Thus, modularity values close to $\mathrm{Q}=0$ indicate a low or null level of community structure; by contrast, values close to $\mathrm{Q}$ $=1$, which is the maximum, indicate a strong presence of community structure. In the case of the projected network, high modularity values suggest that there are structures or modules inside the network that tend to be influenced internally, but not mutually.

In practice, we observe over time that there are increases and decreases of the level of modularity of the network, but they are always between values of 0.1 and 0.2 (see Figure 2(b)), indicating low level of community structure and, consequently, a high level of influence of "all with all", without seeing structures inside the network. However, over time variability is noted, which suggests that certain factors seem to influence the network structure.

4.2.3. Average Path-Length. The average path length $<\mathrm{d}>$ is the average of the shortest distances between all the pairs of nodes in the network; for this, we estimate the value for the projection of the bipartite network monthly [28]. As this is a directed network, we have that

$$
<d>=\frac{1}{N(N-1)} \sum_{i, j=1 . . N, i \neq j} d_{i, j}
$$

where $\mathrm{N}$ is the number of vertices in the network (number of funds in the industry).

Given that the strength of the projection indicates the influence-dependency level on other funds, this value symbolizes the average degree of influence between the funds existing in the market at a given moment. Thus, for example, if at some point in time $d_{i k}$ is low about another period, then it 

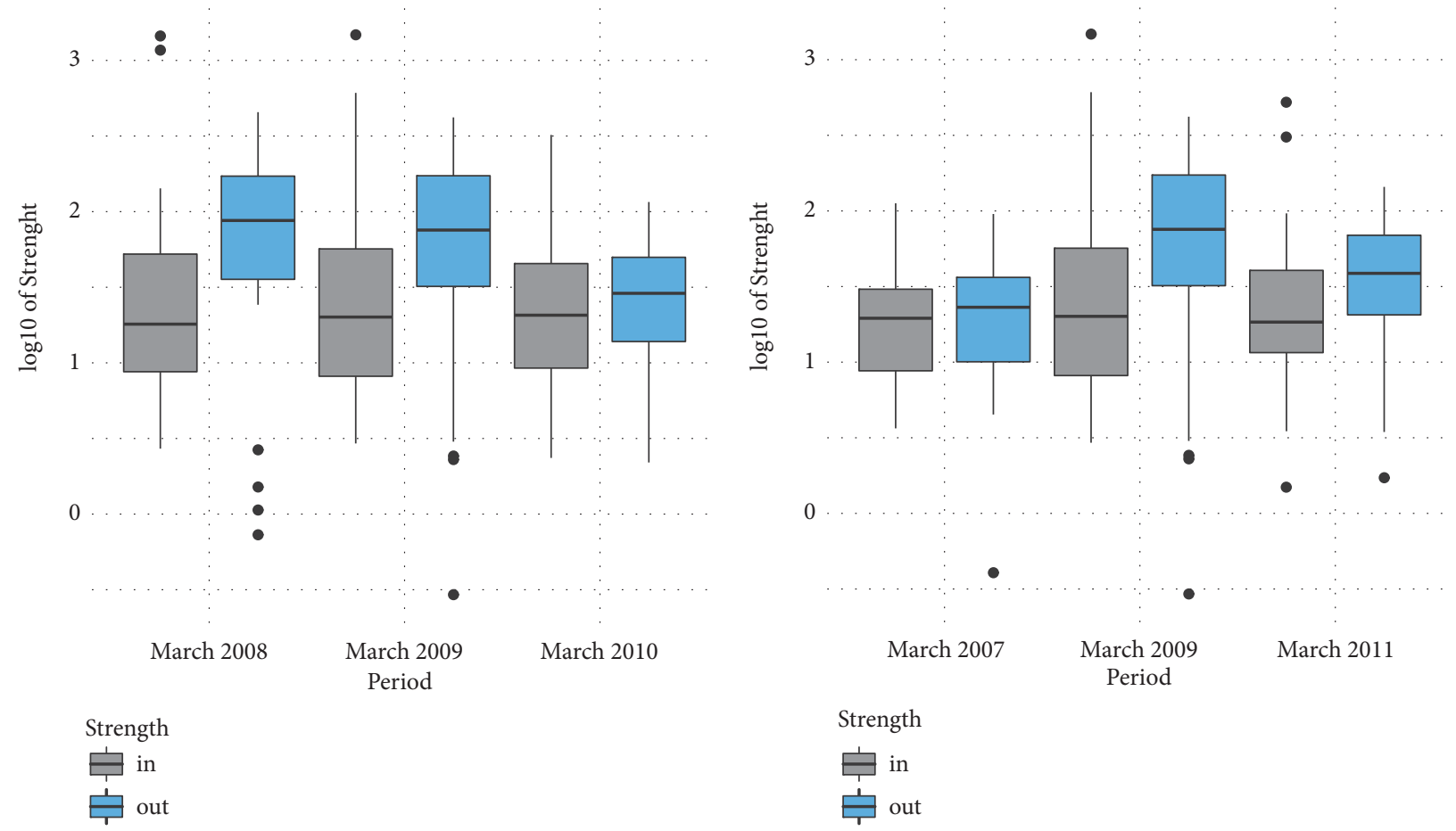

(a) Boxplots of logarithms of strengths-in and strengths-out of the bipartite network projection of mutual funds, 12 months before and after the crisis (March 2008, 2009, and 2010)

(b) Boxplots of logarithms of strengths-in and strengths-out of the bipartite network projection of mutual funds, 24 months before and after the crisis (March 2007, 2009, and 2011)

\section{FiguRE 3}

Case 1
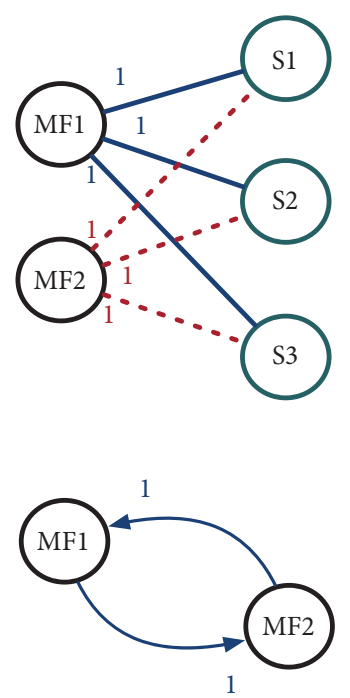

Case 2

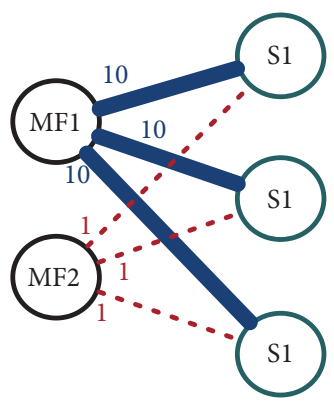

(a) Bipartite Network

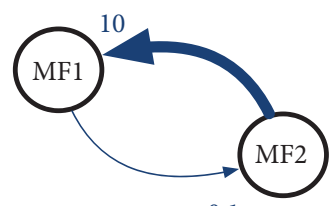

0.1
Case 3
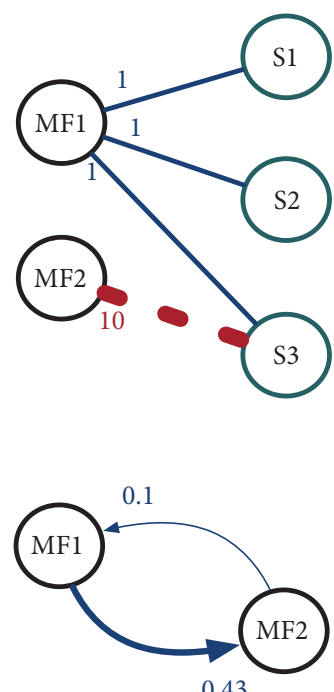

(b) Zhou Projection

Figure 4

can be interpreted that the level of interdependence between funds $i$ and $k$ are lower than at the beginning. As a result, a small $<\mathrm{d}>$ value indicates little interdependence between the funds in the industry at a specific time, whereas higher values indicate a greater interdependence level. Their evolution over time is in Figure 2(b).
4.2.4. Assortativity. Assortativity measures the tendency of nodes to connect with other nodes of the same degree. Thus, nodes with high degrees tend to be connected to each other, and, in the opposite direction, a disassortative network indicates that nodes with high degrees tend to be connected with low-degree nodes [29]. 
In our case, as we are dealing with weighted bipartite networks, we wished to find the degree of assortative mixing in terms of the weights $w_{i j}$ of a fund $i$ on an asset $j$. For this we calculated Pearson's correlation coefficient between the strengths of mutual funds and the shares in the bipartite network for each period [30]. Thus, assortativity levels close to 1 indicate that the mutual funds with high levels of invested capital tend to invest in stocks that are also heavily present in the portfolios of other mutual funds. Otherwise, assortativity values close to - 1 indicate that mutual funds with high levels of investment tend to invest in stocks that are little represented in the portfolios of other funds in the industry.

In practice, it is observed that these values are close to 0.9 (see Figure 2(b)), which indicates that the Chilean mutual fund industry tends to exhibit a kind of elevated preferential attachment, in which the funds' portfolios conform to the level of capital they have and the presence of the stocks in the market. This behavior may be the result of investment strategies that managers follow in a high level of portfolio overlap. These values are similar to that found in [31] in the percentage of shares that firms share with each other and in the Italian bank industry [32].

An explanation of the high levels of assortativity found could be based on the phenomena of herding in the management of investments [33] and the reduced diversity and liquidity of shares available in emerging markets. On the other hand, compensation and career development motivate mutual fund managers to invest in shares in which everyone invests, thus eliminating the possibility of losing money when everyone wins, a very negative event for their remuneration and career development. A second explanation is the limited availability of investment options and liquidity problems. This explains why the funds invest a large amount of money in a few shares, as they manage liquidity risk.

\section{Econometric Analysis}

5.1. Specification of the Model. In this study we focus on the dynamic analysis of the topological behavior of the bipartite network and its projection using elements specific to the mutual fund industry as well as variables related to mutual fund investment management strategies. However, the context in which these investors act is related to the general economic and financial environment, which affects the behavior of the stock market as a whole. Eberhard and others [34] find that the network structure of equity market transactions changes together with variables from the local and international financial environment. Specifically, for the case of the Chilean equity market, the network structure of stock exchange transactions fluctuates with the S\&P 500 index, the blue-chip Chilean index (IPSA), the Chicago Board Options Exchange Market Volatility Index (VIX), the exchange rate between the Chilean peso and the USD dollar (CLP), the emerging market index (MSCI), the oil price (Pe), and the copper price $(\mathrm{Cu})$.

For the case of the factors of the mutual fund industry, we use variables that characterize the industry at aggregate level and at financial level. In the first group, the total number of investors or participants in the industry, the total number of stocks in the portfolios under delegated management, and the total number of mutual funds existing in the market are included. In the second group, variables studied by the literature are incorporated to measure the financial performance and investment abilities of the mutual funds. The size of the funds is incorporated, measured by the market capitalization (In_mcap) and the book-to-market ratio (In_book) [17] the momentum of the performance of the funds, measured by the one-month delayed return (L.performance), and the rotation of the portfolios, measured by turnover (ln_to) [18]; active management of the funds, measured by the active share (ln_as) $[19,20]$; and the liquidity of the assets of the funds, measured by liquidity of the portfolios (In_liq) [21].

As previously mentioned, our hypothesis studies the impact on the topology of the mutual funds bipartite network and its projection of fluctuations in the economic and financial conditions of the capital market, as well as changes in the investment management decisions made by the funds as a result of their role as third-party portfolio managers. According to this, as we indicate in Sections 3.1 and 3.2, the topological variables that study the bipartite network are the variation in degree (vdegfon), the variation in strength (vstrengthb), and the variation in the diversity of the funds (vdiversity). Likewise, for the case of the projected network, we study the variation in strength (vstrengthp), the variation in modularity (vmodularity), the variation in path-length (vpathlenth), and the variation in assortativity (vassortativity).

According to the above, to study the effects of variations on the financial strategies deployed by the mutual funds as a whole and by changes in the mutual funds' industry aggregate variables, we estimate the following econometric model for the bipartite network and its projection:

$$
Y_{t}=\alpha+\beta * X_{t}+\gamma * C_{t}+m_{t}+\varepsilon_{t}
$$

The dependent variable is $Y_{t}$ and represents the variation in the topological variables of the bipartite and the projected networks. $X_{t}$ corresponds to the independent variables associated with the investment decisions of the whole funds and aggregate variables of the industry. $C_{t}$ corresponds to the control variables associated with the economic and financial environment. $m_{t}$ are monthly fixed effects to control for seasonality. All models are estimated with robust standard errors.

5.2. Main Results. To test our hypotheses, the econometric study that is reported next is based on the analysis of the statistical significance between restricted and unrestricted models in order to evaluate whether the changes in the topological variables of the bipartite networks and the projected one are explained by changes in variables related to the financial management of the funds and/or by changes in the variables specific to the mutual fund industry.

\subsubsection{Econometric Models of the Bipartite Network}

(1) Degree. Table 1, column (1), shows that changes in the average diversification of the industry (vdegfon) are jointly associated by changes related to industry-specific variables 


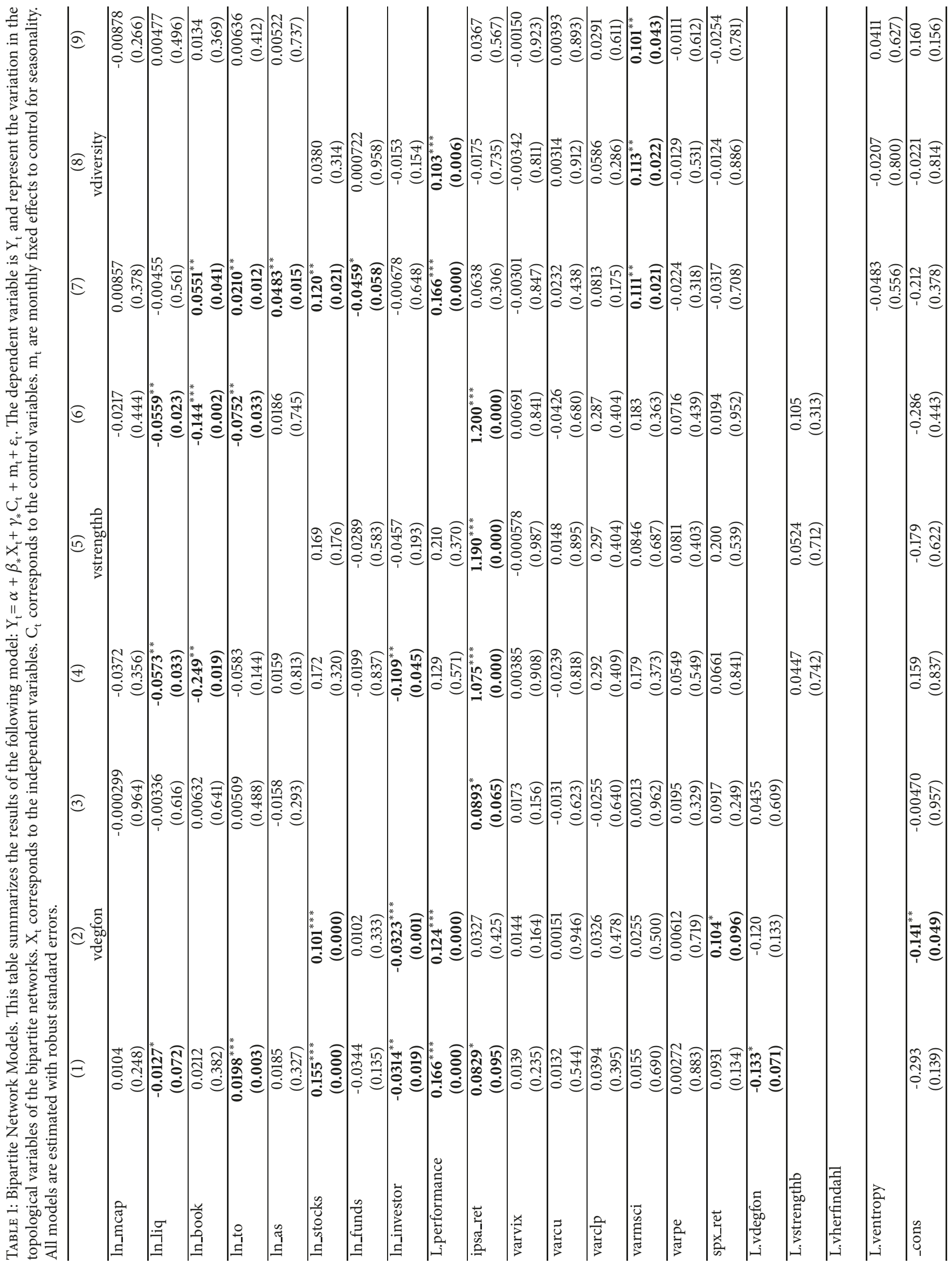




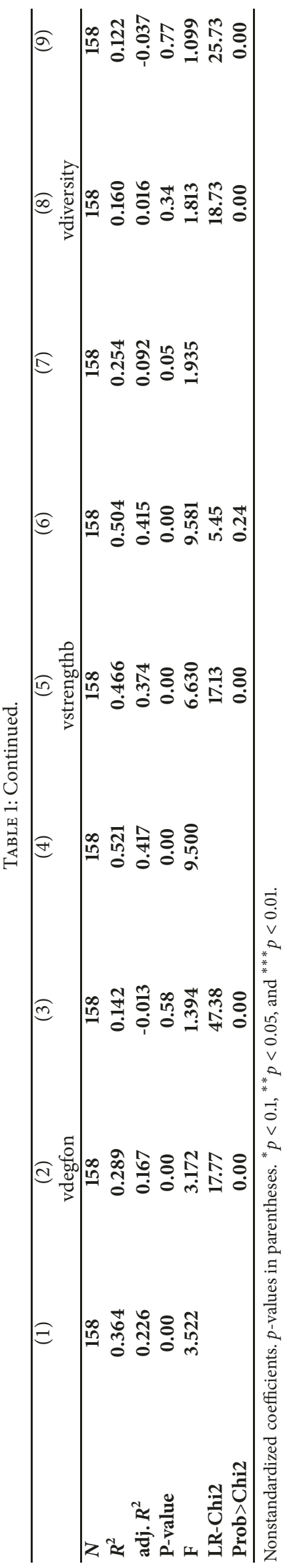


and changes in the mutual funds' investment strategies. Within the first group of variables with statistical significance, highlighted by the magnitude of its effect is the variable average number of stocks within the funds ( $n_{n}$ stocks); a one standard deviation increase in ln_stocks would yield a .79 standard deviation increase in the predicted vdegfon $(\beta=$ 0.79 , normalized coefficient). It is also observed that when the past return of the industry increases (L.perfomance), diversification also does so. The intuition of these results indicates that when the return of the previous month increases, the industry tends to increase the diversification within the funds, this being consistent with an increase in the number of stocks bought by each fund.

Nevertheless, an inverse effect is noted between the number of investors in the industry (In_investors) and the diversification of the funds ( $v$ degfon). In order of magnitude, a one standard deviation increase in In_investors would yield a .53 standard deviation decrease in the predicted $v$ degfon $(\beta=$ -0.53 , normalized coefficient). This result indicates that, in the event of an increase in investors and probably also an increase in the amounts of money managed, mutual funds tend to concentrate the investment in popular or glamour stocks [35], causing the diversification to decrease.

As far as the variables related to the financial management of the funds is concerned, a positive relation can be seen with turnover ( $n_{-} t o$ ) and a negative one with liquidity (ln_liq), with the former being the one that presents the greatest magnitude of impact on the diversification of the industry. Indeed, an increase in a one standard deviation in the turnover causes an increase of 0.4 times in the standard deviation of the diversification $(\beta=0.4$, normalized coefficient). The intuition of this phenomenon is based on a relevant objective of investment management, materialized through the rotation of its assets [21], which consists of managing the diversification of the mutual funds. On the other hand, by increasing the liquidity of the assets bought by the funds, these reduce the diversification of their portfolios, concentrating their investments on fewer assets $(\beta=-0.25$, normalized coefficient).

(2) Strength. In relation to the level of exposure of the mutual funds (vstrengthb), column (6) shows that the changes in the funds' exposure depend exclusively on changes related to investment management variables. Indeed, when the significance test is applied, it is demonstrated that the industryspecific variables do not affect the exposure of the mutual funds $\left(p_{\text {value }}=0.24\right)$. Also, it is observed that when they increase the liquidity ( $\ln l i q)$, book-to-market ratio (ln_book) and turnover (ln_to), the exposure of the funds decreases. When the liquidity of the portfolio assets increases, the funds respond by investing less in these assets, because their expected return is lower [36]. On the other hand, when the book-to-market ratio of the portfolio stocks increases, the funds reduce their exposure, because the prices of the assets are falling, discouraging their appeal [17]. Finally, by increasing the rotation of the portfolios of the funds, the exposure decreases, because the funds reduce the average exposure in each asset. This means, by rotating the portfolio, their investments reassign among a greater number of assets.
These three variables have similar magnitudes, with the book-to-market ratio being the most relevant $(\beta=-0.28$, normalized coefficient).

(3) Diversity. The complexity of the mutual funds network, measured by the diversity index (vdiversity), as in the case of diversification, is dependent on industry-specific variables and the funds' investment management variables. Column (7) shows that there is a positive relation between diversity, the book-to-market ratio ( $\left.\ln _{-} b o o k\right)$, turnover ( $\left.\ln _{-} t o\right)$, and the active share (ln_as) of the mutual funds. Of these three variables related to the financial management of the funds, the one that has the greatest impact is the book-to-market ratio ( $\beta=0.51$, normalized coefficient).

In relation to the effect of the industry-specific variables, it is observed that the numbers of stocks per fund (ln_stocks) and past performance (L.performance) are significant. The importance of the first is highlighted, as its coefficient is similar to the one of the book-to-market ratio $(\beta=0.53$, normalized coefficient). We see that as the number of stocks and past performance increase, the diversity also does, which makes sense, because the greater the availability of stocks to invest, the greater the diversity in terms of portfolio diversification and exposure. On the other hand, a better performance attracts a larger number of participants to the funds [37], causing the funds to invest more [38], and as a result the exposure also increases, increasing the diversity. Interestingly, as the number of funds in the industry increases, the diversity falls. This could be explained because having more funds, the stock of money invested in the industry is distributed among more agents, and therefore the weights $w_{i j}$ tend to decrease.

5.2.2. Econometric Models of the One-Mode Projection. Remembering that the purpose of the projected network is the analysis of the mutual dependency between funds in the industry, the links in this network indicate the degree of dependency that exists between one fund manager and another, unlike the bipartite network, whose links and weights show levels of asset diversification and exposure, respectively. In general terms, the results in Table 2 indicate that changes in the strength, modularity, and assortativity of the projected network depend on both variations in industry variables as well as changes in the funds' financial management variables. However, these variables do not affect the case of path length.

(1) Strength. Table 2, column (1) directly studies the average interdependence level that exists in the industry in a certain period. The significant variables are book-to-market ( $l_{-}$book) and number of funds ( $n_{-}$funds); both are negative magnitudes ( $\beta=-0.56$ and $\beta=-0.55$ respectively, normalized coefficients). This would imply that, by increasing the number of funds in the industry, the interdependence decreases, which could be explained by the fact that, by keeping the exposure constant, by increasing the number of participants in the industry, the average exposure level between them falls, negatively affecting the mutual interdependence. In the case of the book-to-market ratio, the results show that when this falls, it increases the interdependence between 


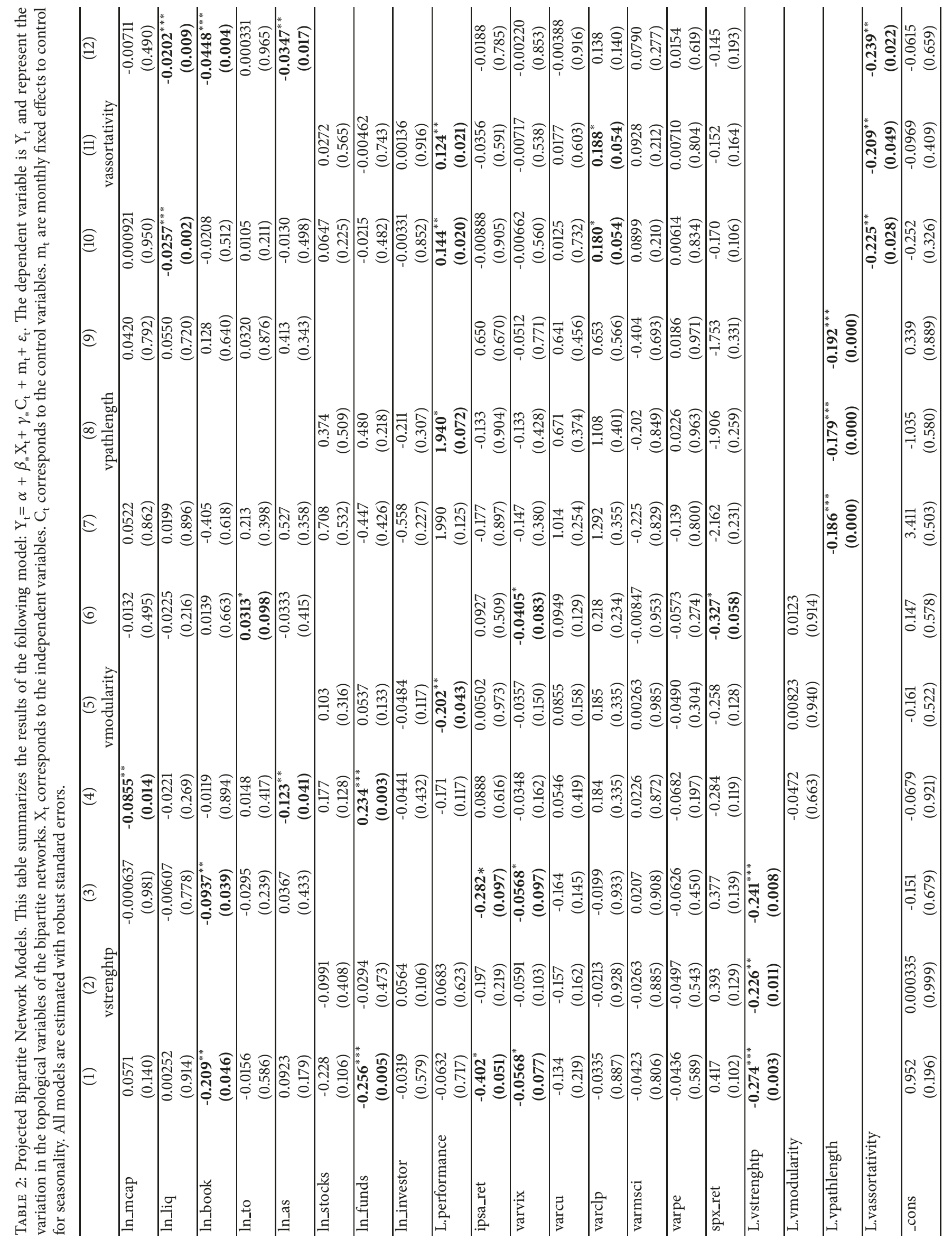




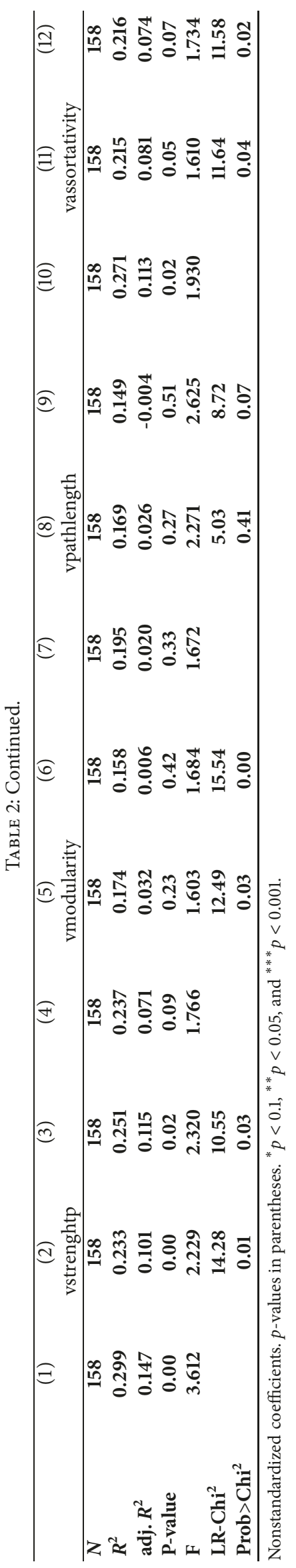


the funds, because the assets are increasing in value, with which the exposure increases and as a result the mutual interdependence increases.

(2) Modularity. In relation to the modularity of the projected network, column (4) shows that the investment management variables of market cap (ln_mcap) and active share (ln_as) negatively affect this network characteristic $(\beta=$ 0.44 and $\beta=-0.40$, respectively, normalized coefficients). The inverse relation between market cap and modularity could be understood by the fact that when the funds begin to buy stocks with low market capitalization (uncommon assets), inevitably their investment portfolios tend to be different from the rest of the industry, and consequently groups of funds appear in the network that have greater similarity to one another. In the first group are those that invest in assets with low market-cap, and, in the second, those that orient their portfolios to assets with high market-cap, with the mutual interdependence between these groups being low.

The inverse relation between active share (ln_as) and modularity can be understood similarly to the previous case. As the active share increases, there are funds whose portfolios begin to be different from those of other investors because they move away from the benchmark when allocating assets into their portfolios, thereby generating a grouping of funds of greater modularity.

The positive relation between number of funds ( $\ln _{-}$funds) and modularity ( $\beta=0.68$ normalized coefficients) has the opposite effect, indicating that when new funds enter the industry, these tend to invest in assets unlike those that funds in the industry already have. Thus, it is observed that the introduction of new funds increases the level of modularity of the projected network, because there are funds with different assets, making it so that mutual funds' clusters that within have the same kind of assets but between them do not.

(3) Assortativity. A high level of assortativity implies that funds with high dependency (high level of strength) are also connected with other funds of high influence (and vice versa). A negative or low assortativity indicates that funds with high dependency are connected with funds of low influence (low level of strength).

Table 2-Column (10) shows that changes in assortativity in the network is negatively affected by changes in the liquidity level ( ln_liq $_{\text {) }}$ and positively by past performance (L.performance) ( $\beta=-0.37$ and $\beta=0.25$, respectively, normalized coefficients). This implies that, in months where the industry increases the liquidity of its mutual funds, they tend to do so by choosing similar stocks (the most liquid), whereas in periods where the industry uses lower liquidity levels, they tend to spread their investments across a larger number of stocks. This aggregate behavior is related to the herding phenomenon that mutual funds exhibit $[37,39]$, a situation where they buy and they sell the same stocks.

On the other hand, when the past performance is positive (L.performance), we observe that assortativity increases. This is due to a good performance being associated with a good decision; as a result, the investment increase in the better stocks amplifies the assortativity between those funds that employ the same investment strategies. By contrast, when the performance is negative, it is natural to observe that the funds change their investment strategies and consequently reduce their interdependence on those funds that had similar strategies.

5.3. Robustness. We provide additional econometrics analyses to provide further insights and to test the robustness of our main results. According to the literature, during the financial crisis of 2008, investors' behavior changed in both the developing and developed financial markets. For example, we observed the liquidity hoarding effect with its resulting impact on prices, returns and assets valuation; and the flightto-quality effect with its direct impact on risky assets and their valuations [1]. Emerging markets were not immune to this phenomenon and suffered more than developed markets.

Accordingly, Table 3 shows models that evaluate the consistency of the previous results, controlling for the possible effects of the financial crisis of 2008. All models include a dummy variable (dum_crisis) that takes the value of 1 for each month in the period from Oct-07 to Oct-09 and zero otherwise $^{7}$. The idea is to corroborate that our results are not the result of the financial turmoil that occurred during that time. As we can see in Table 3 the main results hold when we control for the possible effects of the financial crisis. In other words, the changes in the bipartite network and its projection are driven by variations in the financial decisions of the mutual funds' portfolio managers and changes in the structural characteristics of the mutual fund industry.

\section{Conclusions}

The network literature states that, in context of financial stress, the interconnectedness among financial institutions play a key role in terms of the systemic risk of the market. In these situations, a shock on a node of the system could trigger a collapse of the entire financial network [40]. Usually these shocks have an exogenous origin. For example, a currency devaluation, a sudden hike in interest rates, a sudden fall in the stock markets, or even an unexpected central bank intervention could turn on the alarms of the entire financial market and, in consequence, generate changes in the structure of the financial network. Depending on the topology of the network is how the propagation of the shocks alter the stability and resiliency of the system [41].

Although, the above is a first-order reaction of the market to external conditions, an external shock generates a secondorder reaction from the entities that conform the financial network. Depending on the nature, magnitude, and duration of the financial shock, financial institutions react to maintain their financial viability, preserve clients, minimize exposure, take advantage of price selloffs, or simply hedge financial risks. This reaction modifies their investment strategies and, in consequence, provokes a change in their financial behavior. In turn this response generate a certain kind of chain reaction among the actors of the market that modify the structure of the whole network.

In the above context, the phenomenon of overlapping portfolios among institutional investors takes relevance. In 
TABLE 3: Robustness Models. This table summarizes the results of the following model: $\mathrm{Y}_{\mathrm{t}}=\alpha+\beta_{*} \mathrm{X}_{\mathrm{t}}+\gamma_{*} \mathrm{C}_{\mathrm{t}}+\mathrm{m}_{\mathrm{t}}+\varepsilon_{\mathrm{t}}$. The dependent variable is $Y_{t}$ and represent the variation in the topological variables of the bipartite networks. $X_{t}$ corresponds to the independent variables. $C_{t}$ corresponds to the control variables. $\mathrm{m}_{\mathrm{t}}$ are monthly fixed effects to control for seasonality. All models are estimated with robust standard errors.

\begin{tabular}{|c|c|c|c|c|c|c|}
\hline & \multicolumn{3}{|c|}{ Bipartite Networks } & \multicolumn{3}{|c|}{ Projected Bipartite Networks } \\
\hline & $(1)$ & (2) & (3) & $(4)$ & (5) & (6) \\
\hline & vdegfon & vstrengthb & vdiversity & vstrenghtp & vmodularity & vassortativity \\
\hline \multirow[t]{2}{*}{ ln_mcap } & 0.0127 & -0.0202 & 0.00989 & 0.0565 & $-0.0917^{* * *}$ & 0.000292 \\
\hline & $(0.181)$ & $(0.557)$ & $(0.344)$ & $(0.175)$ & $(0.007)$ & $(0.984)$ \\
\hline \multirow[t]{2}{*}{ ln_liq } & $-0.0119 *$ & $-0.0544^{* *}$ & -0.00409 & 0.00225 & -0.0240 & $-0.0260^{* * *}$ \\
\hline & $(0.091)$ & $(0.037)$ & $(0.602)$ & $(0.925)$ & $(0.235)$ & $(0.003)$ \\
\hline \multirow[t]{2}{*}{ ln_book } & 0.0239 & $-0.141^{* * *}$ & $0.0568^{* *}$ & $-0.209^{* *}$ & -0.0188 & -0.0216 \\
\hline & $(0.323)$ & $(0.005)$ & $(0.039)$ & $(0.048)$ & $(0.829)$ & $(0.493)$ \\
\hline \multirow[t]{2}{*}{ ln_to } & $0.0207^{* * *}$ & $-0.0750^{* *}$ & $0.0215^{* *}$ & -0.0159 & 0.0127 & 0.0102 \\
\hline & $(0.002)$ & $(0.033)$ & $(0.010)$ & $(0.590)$ & $(0.491)$ & $(0.236)$ \\
\hline \multirow[t]{2}{*}{ ln_as } & 0.0204 & 0.0180 & $0.0494^{* *}$ & 0.0918 & $-0.129^{* *}$ & -0.0135 \\
\hline & $(0.273)$ & $(0.756)$ & $(0.013)$ & $(0.189)$ & $(0.031)$ & $(0.487)$ \\
\hline \multirow[t]{2}{*}{ ln_stocks } & $0.165^{* * *}$ & & $0.126^{* *}$ & -0.231 & 0.154 & 0.0620 \\
\hline & $(0.000)$ & & $(0.019)$ & $(0.121)$ & $(0.191)$ & $(0.262)$ \\
\hline \multirow[t]{2}{*}{ ln_funds } & -0.0372 & & $-0.0475^{*}$ & $-0.255^{* * *}$ & $0.243^{* * *}$ & -0.0208 \\
\hline & $(0.106)$ & & $(0.051)$ & $(0.007)$ & $(0.002)$ & $(0.501)$ \\
\hline \multirow[t]{2}{*}{ ln_investor } & $-0.0336^{* *}$ & & -0.00801 & -0.0312 & -0.0394 & -0.00273 \\
\hline & $(0.016)$ & & $(0.593)$ & $(0.602)$ & $(0.499)$ & $(0.881)$ \\
\hline \multirow[t]{2}{*}{ L.performance } & $0.159^{* * *}$ & & $0.162^{* * *}$ & -0.0609 & -0.154 & $0.146^{* *}$ \\
\hline & $(0.000)$ & & $(0.001)$ & $(0.728)$ & $(0.180)$ & $(0.022)$ \\
\hline \multirow[t]{2}{*}{ dum_crisis } & -0.00531 & -0.00630 & -0.00314 & 0.00171 & 0.0130 & 0.00152 \\
\hline & $(0.195)$ & $(0.899)$ & $(0.602)$ & $(0.947)$ & $(0.355)$ & $(0.833)$ \\
\hline \multirow[t]{2}{*}{ ipsa_ret } & 0.0793 & $1.196^{* * *}$ & 0.0618 & $-0.401^{*}$ & 0.0979 & -0.00789 \\
\hline & $(0.115)$ & $(0.000)$ & $(0.324)$ & $(0.053)$ & $(0.587)$ & $(0.915)$ \\
\hline \multirow[t]{2}{*}{ varvix } & 0.0122 & 0.00476 & -0.00406 & $-0.0562^{*}$ & -0.0306 & -0.00607 \\
\hline & $(0.307)$ & $(0.858)$ & $(0.799)$ & $(0.083)$ & $(0.232)$ & $(0.607)$ \\
\hline \multirow[t]{2}{*}{ varcu } & 0.0126 & -0.0449 & 0.0227 & -0.134 & 0.0566 & 0.0127 \\
\hline & $(0.564)$ & $(0.672)$ & $(0.447)$ & $(0.220)$ & $(0.400)$ & $(0.726)$ \\
\hline \multirow[t]{2}{*}{ varclp } & 0.0348 & 0.278 & 0.0783 & -0.0319 & 0.197 & $0.181^{*}$ \\
\hline & $(0.448)$ & $(0.482)$ & $(0.190)$ & $(0.895)$ & $(0.292)$ & $(0.051)$ \\
\hline \multirow[t]{2}{*}{ varmsci } & 0.0148 & 0.182 & $0.111^{* *}$ & -0.0421 & 0.0244 & 0.0901 \\
\hline & $(0.704)$ & $(0.377)$ & $(0.022)$ & $(0.808)$ & $(0.860)$ & $(0.210)$ \\
\hline \multirow[t]{2}{*}{ varpe } & 0.00451 & 0.0742 & -0.0213 & -0.0441 & -0.0738 & 0.00561 \\
\hline & $(0.807)$ & $(0.409)$ & $(0.347)$ & $(0.583)$ & $(0.163)$ & $(0.850)$ \\
\hline \multirow[t]{2}{*}{ spx_ret } & 0.0742 & -0.00386 & -0.0431 & 0.424 & -0.235 & -0.164 \\
\hline & $(0.245)$ & $(0.990)$ & $(0.620)$ & $(0.114)$ & $(0.206)$ & $(0.122)$ \\
\hline \multirow[t]{2}{*}{ L.vdegfon } & $-0.140^{*}$ & & & & & \\
\hline & $(0.062)$ & & & & & \\
\hline L.vstrengthb & & 0.100 & & & & \\
\hline & & $(0.406)$ & & & & \\
\hline L.vdiversity & & & -0.0492 & & & \\
\hline & & & $(0.551)$ & & & \\
\hline L.vstrenghtp & & & & $-0.275^{* * *}$ & & \\
\hline & & & & $(0.004)$ & & \\
\hline L.vmodularity & & & & & -0.0589 & \\
\hline & & & & & $(0.594)$ & \\
\hline L.vassortativity & & & & & & $-0.227^{* *}$ \\
\hline & & & & & & $(0.027)$ \\
\hline _cons & -0.322 & -0.297 & -0.228 & 0.961 & 0.00294 & -0.244 \\
\hline & $(0.110)$ & $(0.475)$ & $(0.353)$ & $(0.197)$ & $(0.996)$ & $(0.338)$ \\
\hline
\end{tabular}


TABLE 3: Continued.

\begin{tabular}{lcccccc}
\hline & & Bipartite Networks & & \multicolumn{3}{c}{ Projected Bipartite Networks } \\
& $(1)$ & $(2)$ & $(3)$ & $(4)$ & $(5)$ & $(6)$ \\
& vdegfon & vstrengthb & vdiversity & vstrenghtp & vmodularity & vassortativity \\
\hline$N$ & $\mathbf{1 5 8}$ & $\mathbf{1 5 8}$ & $\mathbf{1 5 8}$ & $\mathbf{1 5 8}$ & $\mathbf{1 5 8}$ & $\mathbf{1 5 8}$ \\
$\boldsymbol{R}^{2}$ & $\mathbf{0 . 3 6 9}$ & $\mathbf{0 . 5 0 4}$ & $\mathbf{0 . 2 5 5}$ & $\mathbf{0 . 2 9 9}$ & $\mathbf{0 . 2 4 0}$ & $\mathbf{0 . 2 7 1}$ \\
adj. $\boldsymbol{R}^{2}$ & $\mathbf{0 . 2 2 6}$ & $\mathbf{0 . 4 1 0}$ & $\mathbf{0 . 0 8 6}$ & $\mathbf{0 . 1 4 0}$ & $\mathbf{0 . 0 6 8}$ & $\mathbf{0 . 1 0 6}$ \\
P-value & $\mathbf{0 . 0 0}$ & $\mathbf{0 . 0 0}$ & $\mathbf{0 . 0 1}$ & $\mathbf{0 . 0 0}$ & $\mathbf{0 . 0 1}$ & $\mathbf{0 . 0 1}$ \\
F & $\mathbf{3 . 5 2 0}$ & $\mathbf{9 . 3 7 4}$ & $\mathbf{1 . 9 3 8}$ & $\mathbf{3 . 4 4 3}$ & $\mathbf{1 . 8 7 7}$ & $\mathbf{1 . 8 4 0}$ \\
\hline
\end{tabular}

Nonstandardized coefficients. $p$-values in parentheses. ${ }^{*} p<0.1,{ }^{* *} p<0.05$, and ${ }^{* * *} p<0.01$.

these circumstances, when two or more investors share the same financial assets and allocate their investments applying similar financial strategies and invest in the same market, the second-order effect of an external shock, as described earlier, could be a source of disturbance that affects the stability of a financial network.

Following the aforementioned, this study dynamically analyzes the phenomenon of overlapped portfolios by studying the aggregate behavior of the equity mutual funds industry in an emerging market context. These markets are characterized for having well-developed physical financial infrastructure such as central banks, commercial banks and stock exchanges, but at the same time, compared to developed markets, for having less well-developed processes and systems of accounting, governance, and regulation, and mainly less efficient markets with less liquidity [42]. Additionally, they possess a high level of property and control concentration of the firms [43], that becomes them sensible to this phenomenon, and their economic effects, especially during economic and financial downturns.

The main conclusion of this work is that in a developing economies context, the structure of the mutual fund network changes as consequence of external financial and economic factors, and as result of changes in the investment behavior of the entities of the network. Specifically, the topology of the bipartite network of funds and its one-mode projection, is dynamic over time and is correlated with variations in the investment strategies of mutual funds (hypothesis 1) and with industry-specific variables (hypothesis 2). From this perspective, changes in macroeconomic and financial conditions, in conjunction with changes in the mutual fund's industry context, promote changes in the funds' investment strategies, that trigger modifications in the fund's network structure.

On the other hand, we believe that there is an interesting vein of study that consists of studying the richness of the information contained in the directed network from the resulting one-mode projection. An analysis of the structural diversity of the network of interdependencies between funds using the assortative or dissasortative nature of the edges that compose it [44], would reveal interesting information on changes in dependence and influence between components of the industry.

Our results evidence new factors that alter the stability and the systemic risk of financial systems that have not yet been studied by the literature in this segment of institutional investors in an emerging market. These results are interesting because the equity portfolios we analyzed in this study fall within the characteristic of overlapped portfolios, confirming the existence of a channel of contagion generated by the aggregate investment behavior of the entities belonging to the network. Similar results are showed by the network literature that study the effects of the interconnectedness of financial institutions and the propagation of shocks over the systemic risk of the financial market [40, 41, 45]. From a policy and regulator point of view, this evidence highlights that improving the knowledge of overlapping portfolios in emerging markets, is a fundamental element to a better understanding of the risks and magnitudes of financial and economic contagions with respect to the likelihood of their occurrence and extension, and their relation to the number and density of the connections within the financial system.

From a financial perspective, our research is related to the study of herding among investors. As this literature states, this phenomenon can exacerbate the volatility levels in the market, destabilizing it, increase the fragility of the financial system, and eventually, generate assets bubbles [46]. This line of research indicates that under certain financial and market conditions, investors exhibit herd behavior in which they do not only apply the same investment strategies of their peers, but they also copy their same buy and sell decisions of financial assets [33, 47, 48]. To our best understanding, the channel evidenced in this study has not yet been linked to the herd behavior literature, despite having similarities. For example, the level of herd behavior among mutual funds increases during high periods of volatility and price downturns [39], precisely when financial shocks disturb the markets. An alternative to study the problem of herding could consider a more detailed analysis of the assortativity of the bipartite network of funds and stocks when considering higher order assortativity measures that could describe new topological characteristics of the network [49].

Gaining a deeper knowledge of how herding could influence the structure of the mutual funds networks will facilitate a better comprehension of the channels for transmission of the systemic risk associate with this financial behavior. However, the financial literature has studied mutual funds extensively for both their size and importance in the delegated portfolio management industry, we believe that this venue of research in conjunction with the perspective of network analysis, has much to contribute to the preservation of the financial stability, especially in developing markets. 


\section{Appendix}

\section{Relationship between the Bipartite Network and Its Projection in the Mutual Funds Domain}

This appendix shows the relationship between a bipartite network of mutual funds and stocks, and their corresponding projection using the Zhou et. al. [15] method. For this, we take as an example three simple bipartite networks, in which there are two mutual funds, MF1 and MF2, which invest in three possible stocks, namely S1, S2 and S3.

Figure 4(a), shows the three bipartite networks and their respective projections in the mutual funds domain in Figure 4(b). For clarity of notation, we will distinguish $w_{i j}$ as the weight of the bipartite network between the mutual fund $i$ and stock $j$, while $w_{i k}^{p}$ is the weight of the directed network, resulting from the projection of the bipartite network, indicating the influence that the mutual fund $k$ has on the mutual fund $i$ (or that it is the same, the mutual fund $i$ dependence of the mutual fund $k$ ).

In case 1 , we have that mutual funds are equally exposed since they invest the same amount of money on all the three stocks. In this case, there is a symmetrical weighted bipartite network. Thus, the weights $w_{i j}=1$ of the bipartite network for funds $i=1,2$ and for stocks $j=1,2,3$. It is not surprising that the corresponding projection indicates that $w_{12}^{p}=w_{21}^{p}$. That is, the influence that the MF1 fund has on the MF2 fund (given by $w_{21}^{p}$ ) is the same as the influence that MF2 has on MF1 (given by $w_{12}^{p}$ ).

In case 2, MF1 invests an equal sum of money in the three stocks, so that $w_{i j}=10$ for $j=1,2,3$. However, MF2 also invests in the three stocks equitably, but one tenth of what MF1 does, so $w_{2 j}=1$ for $j=1,2,3$. In this case, mutual funds invest their money in the same assets, but in asymmetrical way. The result of the projection is such that $w_{21}^{p}=10$, while $w_{12}^{p}=0.1$. In other words, the influence that MF1 has on MF2 is 100 times greater than the influence that MF2 has on MF1. This indicates that a highly exposed mutual fund with a high investment and diversification in assets in relation to another well diversified mutual fund, but not so exposed in terms of money in the same assets, produces in the projection a high value of strength, indicating the strong effect of the influence of the first mutual fund over the rest.

Case 3 is different, MF1 is more diversified than MF2, but less exposed in their allocations. That is to say, the weights of the bipartite network are asymmetrical as well as the connections, because the degree of MF2 is different from the degree of MF1. Thus, in this case, $w_{1 j}=1$ for all $j=1,2,3$, and $w_{23}=10$ while $w_{21}=w_{22}=0$. MF1 is less exposed, but it is well diversified, while MF2 is highly exposed but poorly diversified. The projection result indicates that $w_{21}^{p}=0.1$ and $w_{12}^{p}=0.43$. In this case, the influence that MF2 has on MF1 is 4.3 times stronger than the influence that MF1 has on MF2. This is because, even when MF2 is not very diversified, it has a high amount of investment in S3. As we increase the exposure values of MF1 but keeping its diversification, the influence of MF2 in relation to MF1 will decrease, until MF1 becomes more influential than MF2.

\section{Data Availability}

The data used to support the findings of this study are available from the corresponding author upon request.

\section{Conflicts of Interest}

The authors declare that they have no conflicts of interest regarding the publication of this paper.

\section{Acknowledgments}

The authors would like to thank CONICYT-Chile under grant Fondecyt 11160072 (Mauricio A. Valle), for financially supporting this research.

\section{Endnotes}

1. The impact of financial assets on the propagation of shocks is a significant subject in risk analysis. Although most of the literature on financial networks concentrates on the analysis of interbank loans networks and its response to shocks at assets level, for example, firesales; the propagation of shocks through more densely connected networks, such as the networks established through financial assets is greater. Delpini and others [8] indicated that as a consequence of a more diversified pattern of investment - like in pension funds and mutual funds - a more densely connected network serves as a mechanism of propagation of shocks, increasing systemic risk as a result.

2. ICI Fact Book 2017 (www.icifactbook.org).

3. For example, by analyzing the degree distribution and strength of the stocks in a portfolio, it may be determined whether the classic characteristic of free scale property is fulfilled, in which most of the stocks are in the hands of a few funds and where many funds have a few stocks.

4. Using exact positions of each stock over time allows us to avoid their inference from the financial reports of each mutual fund, thereby avoiding unrealistically dense networks and biased underestimation of systemic risk $[5]$.

5. For any period of time of the bipartite network, the sum of all the strengths of the funds must be equal to the sum of the strengths of the stocks. That is equivalent to saying that the amount of money invested by the funds must be the same as the amount of money that is invested in the stocks. For the projection of the bipartite network in mutual funds, the mean of the in-strength is the same as the mean of the out-strength, since the direction in which an edge enters a node is equivalent to the direction in which another node exits, which is why the all the resources are retained in the system. 
6. We use March 2009 as a reference point because the $S \& P$ 500 Index reached 666.79 points, being this value the minimum during the financial crisis.

7. During this period, the stocks markets experienced the worst performance in terms of return and volatility.

\section{References}

[1] A. G. Haldane, "Rethinking the financial network," in Fragile Stabilität - stabile Fragilität, pp. 243-278, 2013.

[2] R. Greenwood, A. Landier, and D. Thesmar, "Vulnerable banks," Journal of Financial Economics, vol. 115, no. 3, pp. 471-485, 2015.

[3] P. Glasserman and H. P. Young, "Contagion in financial networks," Journal of Economic Literature, vol. 54, no. 3, pp. 779831, 2016.

[4] M. Pollak and Y. Guan, "Partially overlapping ownership and contagion in financial networks," Complexity, vol. 2017, Article ID 9895632, 16 pages, 2017.

[5] M. J. Straka, G. Caldarelli, T. Squartini, and F. Saracco, "From ecology to finance (and back?): recent advancements in the analysis of bipartite networks," Journal of Statistical Physics, vol. 173, no. 3-4, pp. 1252-1285, 2018.

[6] M. Elliott, B. Golub, and M. O. Jackson, "Financial networks and contagion," American Economic Review, vol. 104, no. 10, pp. 3115-3153, 2014.

[7] F. Caccioli, P. Barucca, and T. Kobayashi, "Network models of financial systemic risk: a review," Journal of Computational Social Science, vol. 1, no. 1, pp. 81-114, 2017.

[8] D. Delpini, S. Battiston, G. Caldarelli, and M. Riccaboni, "The Network of US Mutual Fund Investments: Diversification, Similarity and Fragility throughout the Global Financial Crisis," 2018, https://arxiv.org/abs/1801.02205.

[9] H. Markowitz, "Portfolio selection," The Journal of Finance, vol. 7, no. 1, pp. 77-91, 1952.

[10] P. Glasserman and H. P. Young, "How likely is contagion in financial networks?" Journal of Banking \& Finance, vol. 50, pp. 383-399, 2015.

[11] S. Battiston, J. B. Glattfelder, D. Garlaschelli, F. Lillo, and G. Caldarelli, "The structure of financial networks," in Network Science, pp. 131-163, Springer, London, UK, 2010.

[12] S. Battiston and M. Catanzaro, "Statistical properties of corporate board and director networks," The European Physical Journal B, vol. 38, no. 2, pp. 345-352, 2004.

[13] S. Battiston, J. F. Rodrigues, and H. Zeytinoglu, "The network of inter-regional direct investment stocks across Europe," Advances in Complex Systems (ACS), vol. 10, no. 1, pp. 29-51, 2007.

[14] M. Boss, H. Elsinger, M. Summer, and S. Thurner, "Network topology of the interbank market," Quantitative Finance, vol. 4, no. 6, pp. 677-684, 2004.

[15] T. Zhou, J. Ren, M. Medo, and Y. C. Zhang, "Bipartite network projection and personal recommendation," Physical Review E: Statistical, Nonlinear, and Soft Matter Physics, vol. 76, no. 4, Article ID 046115, 2007.

[16] A. Barrat, M. Barthélemy, R. Pastor-Satorras, and A. Vespignani, "The architecture of complex weighted networks," Proceedings of the National Acadamy of Sciences of the United States of America, vol. 101, no. 11, pp. 3747-3752, 2004.

[17] E. F. Fama and K. R. French, "The cross-section of expected stock returns," The Journal of Finance, vol. 47, no. 2, pp. 427-465, 1992.
[18] M. M. Carhart, "On persistence in mutual fund performance," Journal of Finance, vol. 52, no. 1, pp. 57-82, 1997.

[19] K. J. M. Cremers and A. Petajisto, "How active is your fund manager a new measure that predicts performance," Review of Financial Studies, vol. 22, no. 9, pp. 3329-3365, 2009.

[20] A. Petajisto, "Active share and mutual fund performance," Financial Analysts Journal, vol. 69, no. 4, pp. 73-93, 2013.

[21] J. Lavin and N. Magner, "Reversing the question: on what does the turnover of mutual funds depend? evidence from equity mutual funds in Chile," Emerging Markets Finance \& Trade, vol. 50, no. 5, pp. 110-129, 2014.

[22] A. Khorana, H. Servaes, and P. Tufano, "Explaining the size of the mutual fund industry around the world," Journal of Financial Economics, vol. 78, no. 1, pp. 145-185, 2005.

[23] L. Stracca, "Delegated portfolio management: A survey of the theoretical literature," Journal of Economic Surveys, vol. 20, no. 5, pp. 823-848, 2006.

[24] C. E. Shannon, "A mathematical theory of communication," Bell Labs Technical Journal, vol. 27, pp. 379-423, 1948.

[25] L.-F. Bersier, C. Banašek-Richter, and M.-F. Cattin, "Quantitative descriptors of food-web matrices," Ecology, vol. 83, no. 9, pp. 2394-2407, 2002.

[26] M. Newman and M. Girvan, "Finding and evaluating community structure in networks," Physical Review E, vol. 69, no. 2, pp. $1-16,2004$

[27] M. E. Newman, "Mixing patterns in networks," Physical Review E: Statistical, Nonlinear, and Soft Matter Physics, vol. 67, no. 2, Article ID 026126, 2003.

[28] R. Albert and A. Barabási, "Statistical mechanics of complex networks," Reviews of Modern Physics, vol. 74, no. 1, pp. 47-97, 2002.

[29] E. Estrada and P. Knight, A First Course in Network Theory, Oxford University Press, USA, 2015.

[30] M. Newman, "Assortative mixing in networks," Physical Review Letters, vol. 89, no. 20, Article ID 208701, 2002.

[31] G. Rotundo and A. M. D'Arcangelis, "Ownership and control in shareholding networks," Journal of Economic Interaction and Coordination, vol. 5, no. 2, pp. 191-219, 2010.

[32] G. De Masi, G. Iori, and G. Caldarelli, "Fitness model for the Italian interbank money market," Physical Review E: Statistical, Nonlinear, and Soft Matter Physics, vol. 74, no. 6, Article ID 066112, 2006.

[33] M. Grinblatt, S. Titman, and R. Wermers, "Momentum investment strategies, portfolio performance, and herding: A study of mutual fund behavior," The American Economic Review, pp. 1088-1105, 1995.

[34] J. Eberhard, J. F. Lavin, and A. Montecinos-Pearce, "A networkbased dynamic analysis in an equity stock market," Complexity, vol. 2017, Article ID 3979836, 16 pages, 2017.

[35] J. Y. Campbell, C. Polk, and T. Vuolteenaho, "Growth or glamour? Fundamentals and systematic risk in stock returns," Review of Financial Studies, vol. 23, no. 1, pp. 305-344, 2010.

[36] L. Pástor and R. F. Stambaugh, "Liquidity risk and expected stock returns," Journal of Political Economy, vol. 111, no. 3, pp. 642-685, 2003.

[37] V. A. Warther, "Aggregate mutual fund flows and security returns," Journal of Financial Economics, vol. 39, no. 2-3, pp. 209-235, 1995.

[38] M. Grinblatt, S. Titman, and R. Wermers, "Momentum investment strategies, portfolio performance, and herding: a study of 
mutual fund behavior," American Economic Review, vol. 85, no. 5, pp. 1088-1105, 1995.

[39] J. F. Lavin and N. S. Magner, "Herding in the mutual fund industry: evidence from Chile," Academia Revista Latinoamericana de Administracion, vol. 27, no. 1, pp. 10-29, 2014.

[40] R. Cerqueti, G. P. Clemente, and R. Grassi, "Systemic risk assessment through high order clustering coefficient," 2018, https://arxiv.org/abs/1810.13250.

[41] M. D’Errico, D. Felletti, and R. Grassi, "Shock propagation and the topology of complex networks," Tech. Rep., Dipartimento di Metodi Quantitativi per le Scienze Economiche ed Aziendali, Università degli studi di Milano Bicocca Working Papers, 2010.

[42] C. Kearney, "Emerging markets research: Trends, issues and future directions," Emerging Markets Review, vol. 13, no. 2, pp. 159-183, 2012.

[43] M. P. Abreu, R. Grassi, and R. R. Del-Vecchio, "Structure of control in financial networks: An application to the Brazilian stock market," Physica A: Statistical Mechanics and Its Applications, vol. 522, pp. 302-314, 2019.

[44] J. G. Foster, D. V. Foster, P. Grassberger, and M. Paczuski, "Edge direction and the structure of networks," Proceedings of the National Acadamy of Sciences of the United States of America, vol. 107, no. 24, pp. 10815-10820, 2010.

[45] G. P. Clemente, R. Grassi, and C. Pederzoli, "Networks and market-based measures of systemic risk: the European banking system in the aftermath of the financial crisis," Journal of Economic Interaction and Coordination, pp. 1-23, 2019.

[46] S. Bikhchandani and S. Sharma, "Herd behavior in financial markets," IMF Staff Papers, vol. 47, no. 3, pp. 279-310, 2000.

[47] J. Lakonishok, A. Shleifer, and R. W. Vishny, "The impact of institutional trading on stock prices," Journal of Financial Economics, vol. 32, no. 1, pp. 23-43, 1992.

[48] R. Wermers, "Mutual fund herding and the impact on stock prices," The Journal of Finance, vol. 54, no. 2, pp. 581-622, 1999.

[49] A. Arcagni, R. Grassi, S. Stefani, and A. Torriero, "Higher order assortativity in complex networks," European Journal of Operational Research, vol. 262, no. 2, pp. 708-719, 2017. 


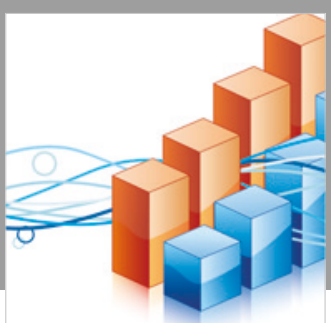

Advances in

Operations Research

\section{-n-m}
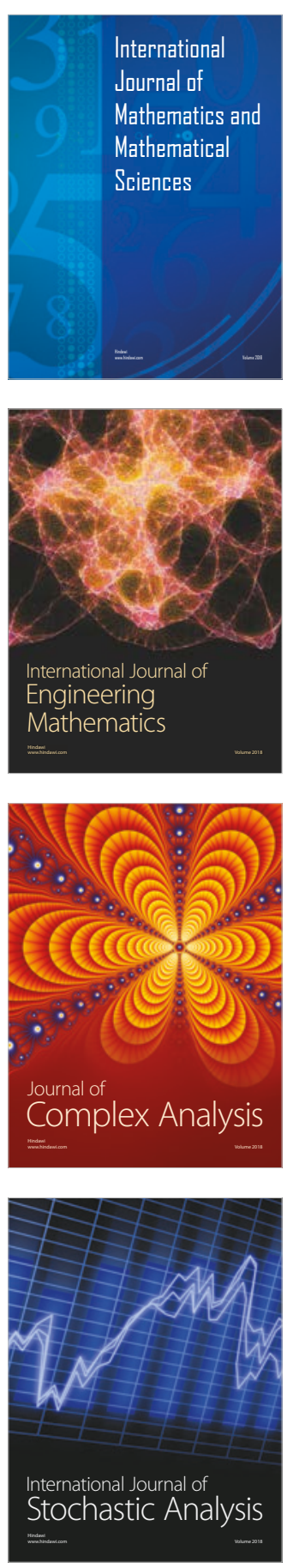
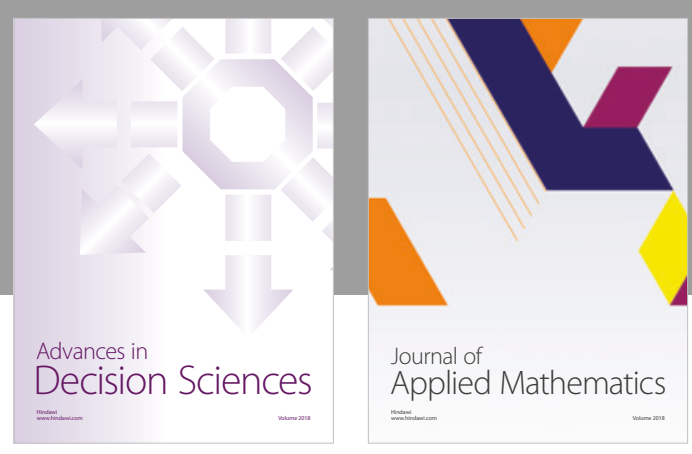

Journal of

Applied Mathematics
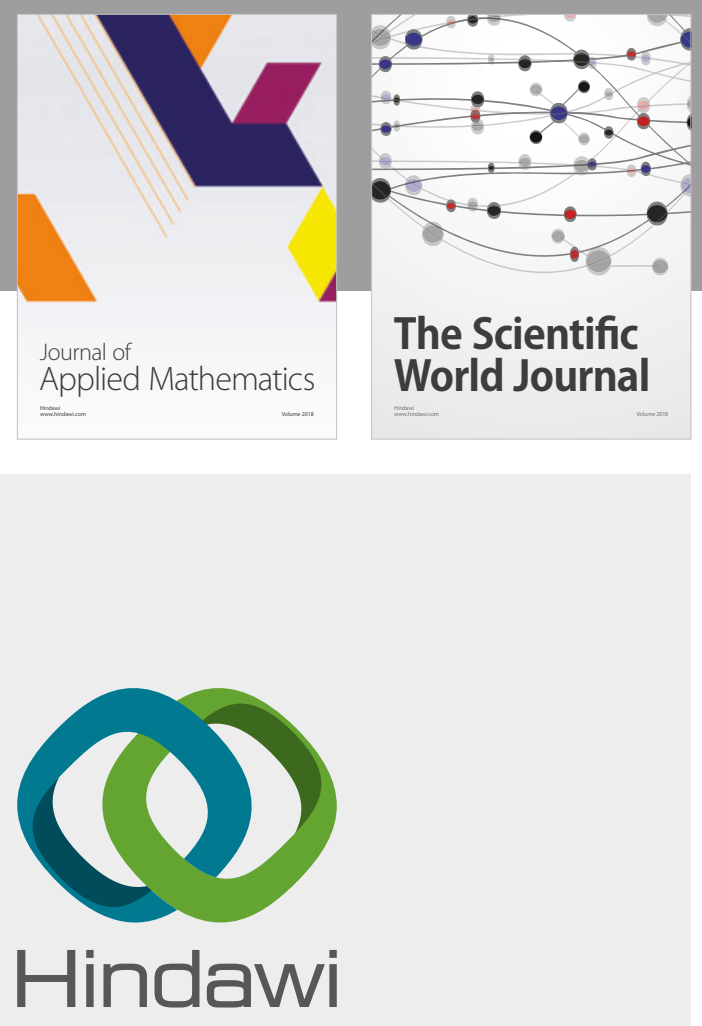

Submit your manuscripts at

www.hindawi.com

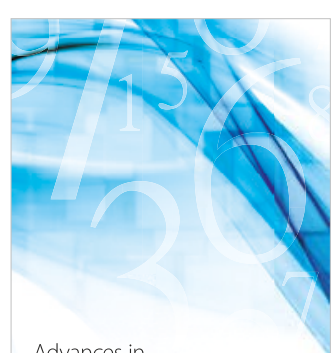

Advances in
Numerical Analysis
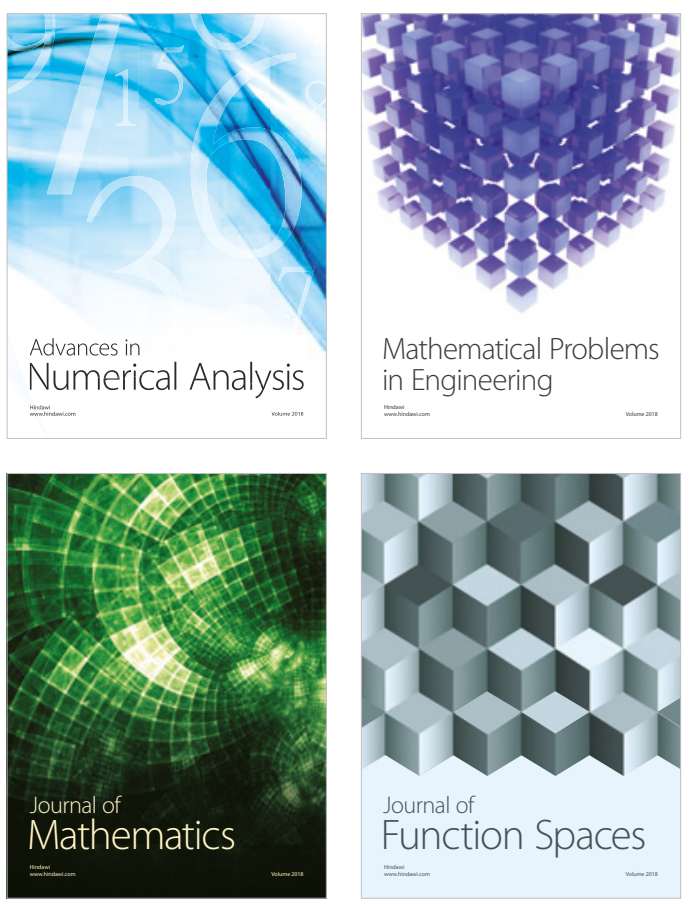

Mathematical Problems in Engineering

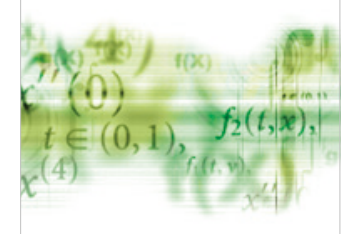

International Journal of

Differential Equations

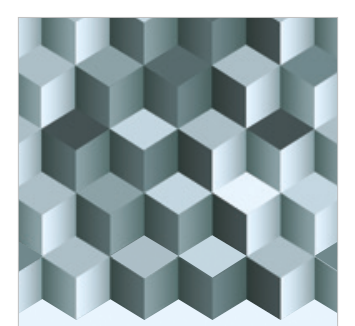

Journal of

Function Spaces
The Scientific

World Journal

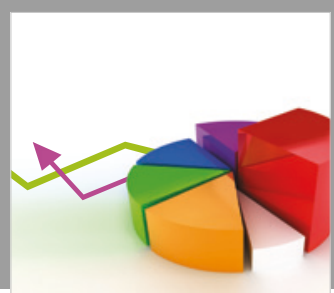

Journal of

Probability and Statistics
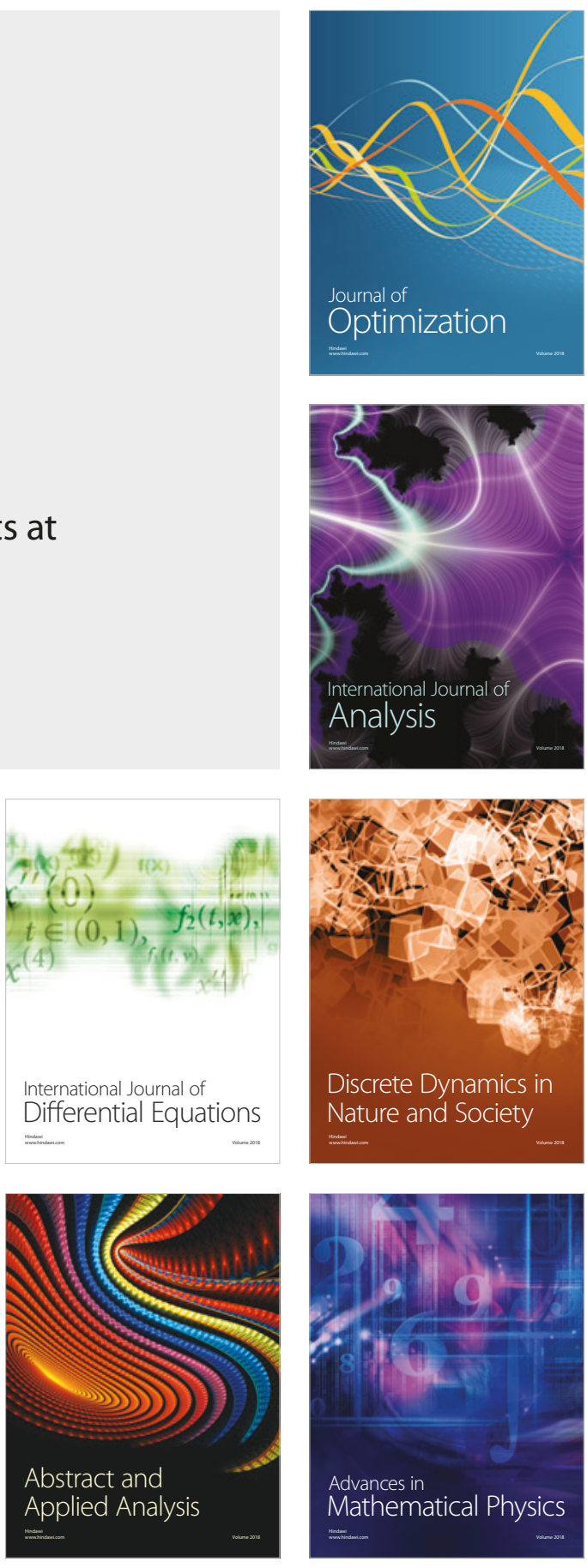